SANDIA REPORT

SAND2011-0973

Unclassified Unlimited Release

Printed February 2011

Supersedes SAND2010-1463

Dated February 2010

\title{
Sandia National Laboratories, California Hazardous Materials Management Program Annual Report
}

\section{February 2011}

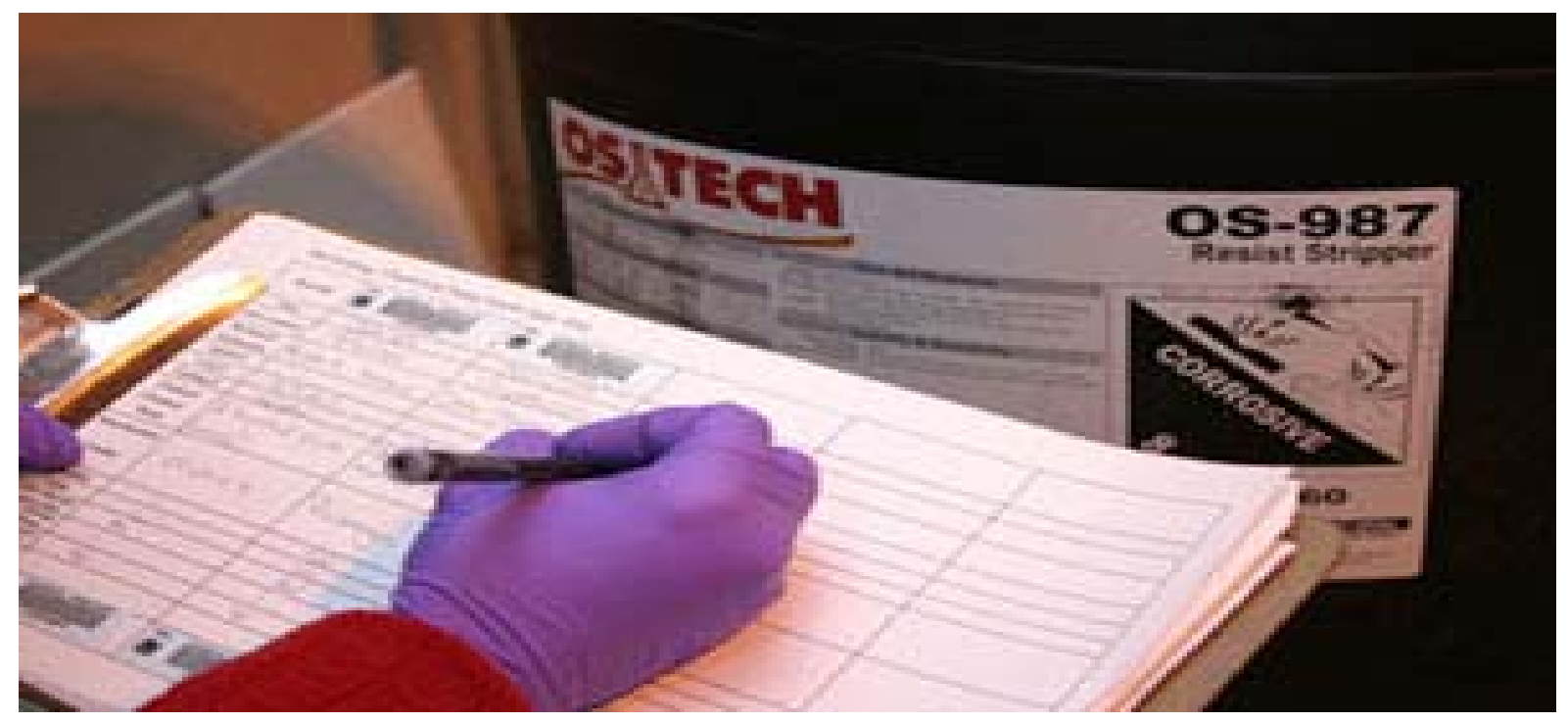

Mark E. Brynildson, (Hazardous Materials Management Program Lead)

Prepared by

Sandia National Laboratories

PO Box 969 MS 9902

Livermore, California 94551-0969

Sandia National laboratories is a multi-program laboratory managed and operated by Sandia Corporation, a wholly owned subsidiary of Lockheed Martin Corporation, for the United States Department of Energy's

National Nuclear Security Administration under contract DE-AC04-94AL85000.

Approved for public release, further dissemination unlimited

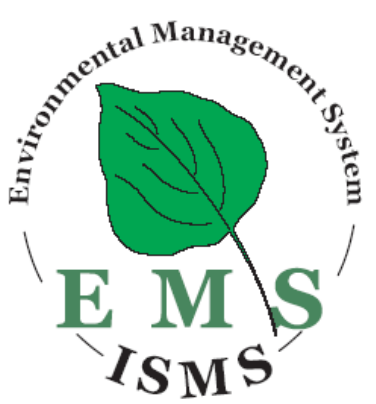

\section{Sandia National Laboratories}


Issued by Sandia National Laboratories, operated for the United States Department of Energy by Sandia Corporation.

NOTICE: This report was prepared as an account of work sponsored by an agency of the United States Government. Neither the United States Government, nor any agency thereof, nor any of their employees, nor any of their contractors, subcontractors, or their employees, make any warranty, express or implied, or assume any legal liability or responsibility for the accuracy, completeness, or usefulness of any information, apparatus, product, or process disclosed, or represent that its use would not infringe privately owned rights. Reference herein to any specific commercial product, process, or service by trade name, trademark, manufacturer, or otherwise, does not necessarily constitute or imply its endorsement, recommendation, or favoring by the United States Government, any agency thereof, or any of their contractors or subcontractors. The views and opinions expressed herein do not necessarily state or reflect those of the United States Government, any agency thereof, or any of their contractors.

Printed in the United States of America. This report has been reproduced directly from the best available copy.

Available to DOE and DOE contractors from

U.S. Department of Energy

Office of Scientific and Technical Information

P.O. Box 62

Oak Ridge, TN 37831

Telephone: (865) 576-8401

Facsimile: (865) 576-5728

E-Mail: reports@adonis.osti.gov

Online ordering: http://www.doe.gov/bridge

Available to the public from

U.S. Department of Commerce

National Technical Information Service

5285 Port Royal Road

Springfield, VA 22161

Telephone: (800) 553-6847

Facsimile: (703) 605-6900

E-Mail: $\quad$ orders@ntis.fedworld.gov

Online order: http://www.ntis.gov/ordering.htm
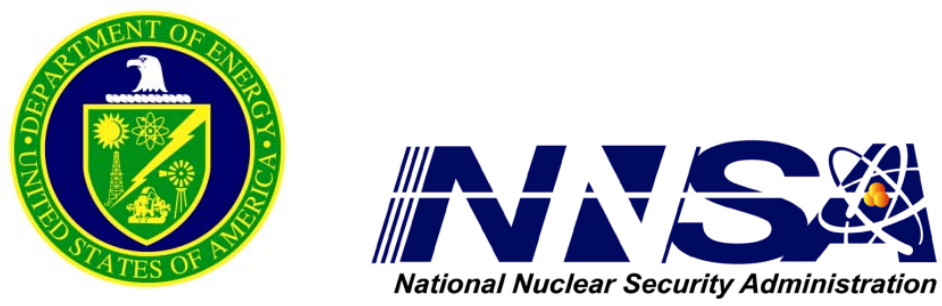
SAND2011-0973

Unclassified Unlimited Release

Printed February 2011

\title{
Sandia National Laboratories, California Hazardous Materials Management Program Annual Report February 2011
}

\author{
Mark E. Brynildson, \\ Hazardous Materials Management Program Lead \\ Environmental Management Department \\ Sandia National Laboratories, California
}

\begin{abstract}
The annual program report provides detailed information about all aspects of the Sandia National Laboratories, California (SNL/CA) Hazardous Materials Management Program. It functions as supporting documentation to the SNL/CA Environmental Management System Program Manual. This program annual report describes the activities undertaken during the calender past year, and activities planned in future years to implement the Hazardous Materials Management Program, one of six programs that supports environmental management at SNL/CA.
\end{abstract}




\section{Acknowledgement}

The author thanks Gary Shamber, Manager, Environmental Management Department, Susanne Ayers, Hazardous Materials Management Program Senior Technologist and the Environmental Management Department personnel for their leadership, guidance and support in the responsible stewardship of the environmental resources in our care. 
Table of Contents

0 SUMMARY OF DOCUMENT CHANGES ....................................................................

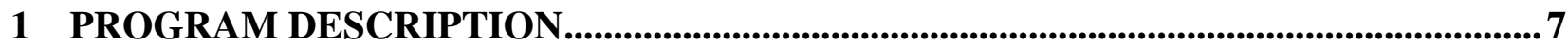

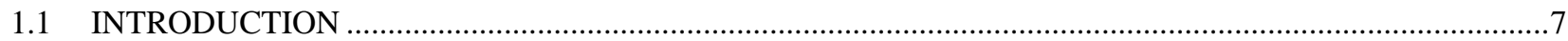

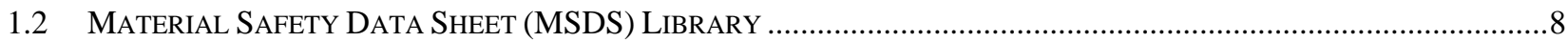

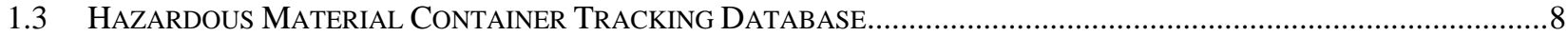

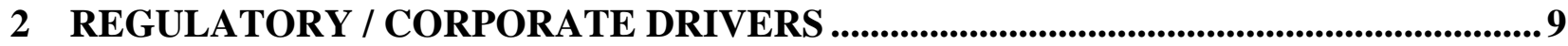

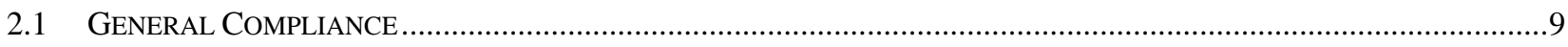

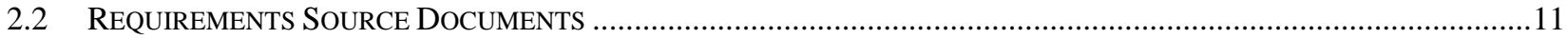

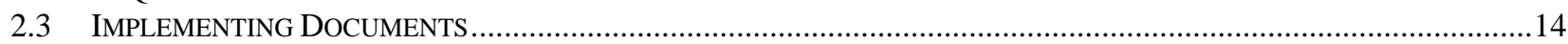

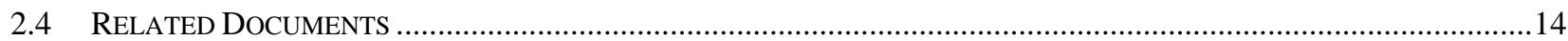

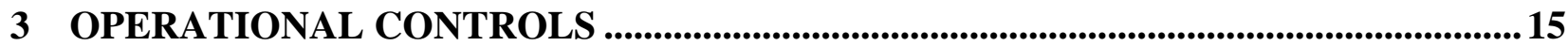

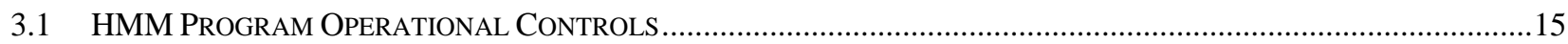

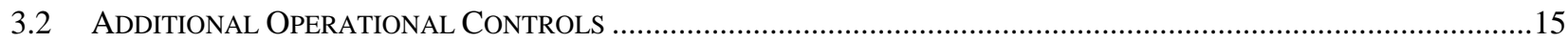

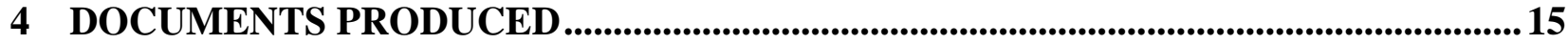

5 APPROVED JOB DESCRIPTIONS / CURRENT ASSIGNMENTS .............................. 16

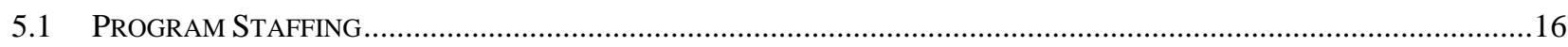

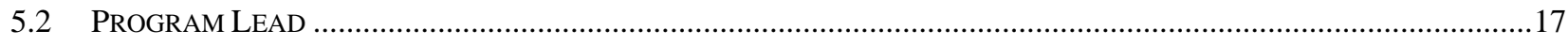

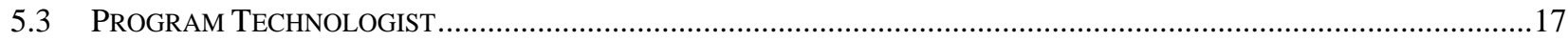

5.4 STUDENT INTERN ..............................................................................................................................17

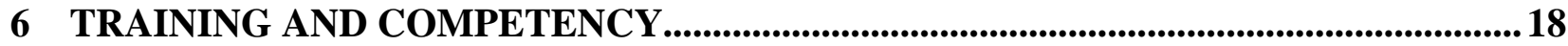

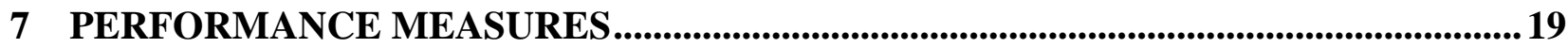

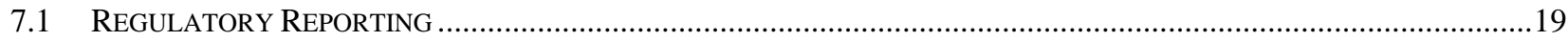

7.2 ANNUAL HAZARDOUS MATERIAL INVENTORY RECONCILIATION “FOUND” RATE ................................................19

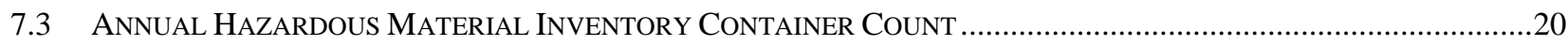

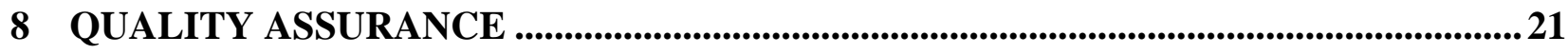

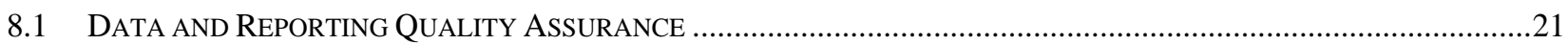

8.2 ANNUAL HAZARDOUS MATERIAL INVENTORY RECONCILIATION..................................................................21

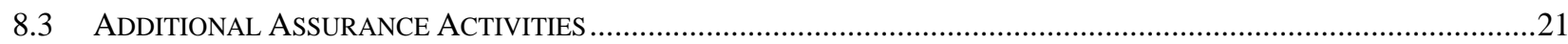

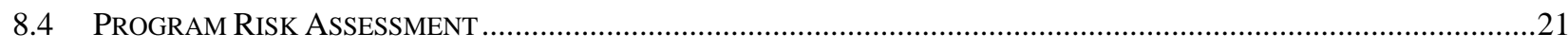

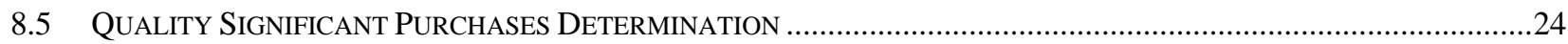

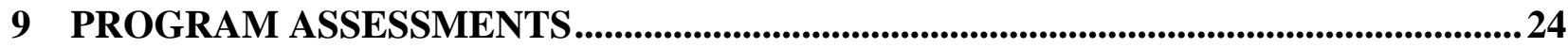

9.1 FOLLOW-UP ON THE 2009 PROGRAM SELF-ASSESSMENT ….......................................................................24

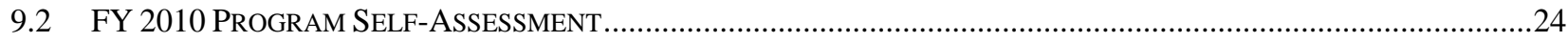

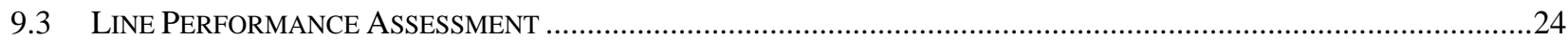

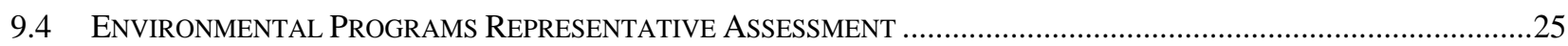

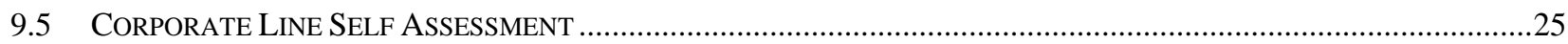

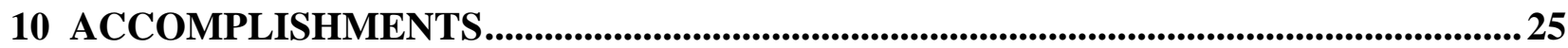

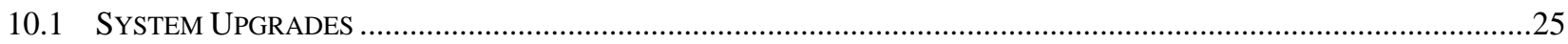

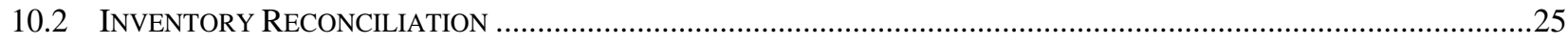

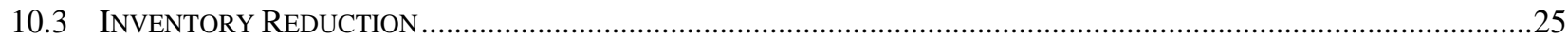

10.4 EMERGENCY MANAGEMENT - HAZARDS SURVEY \& EPHA ……...................................................................25

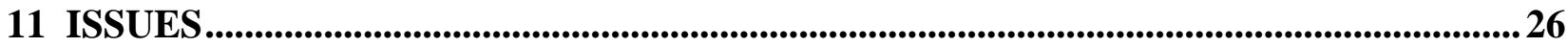




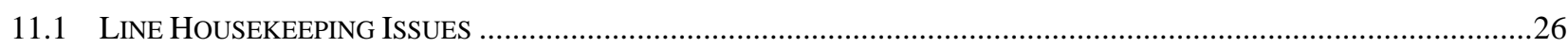

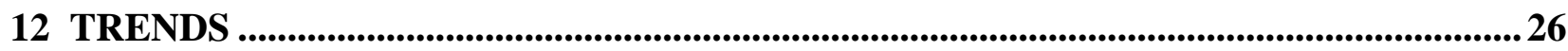

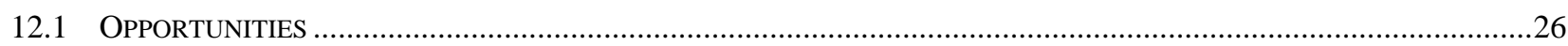

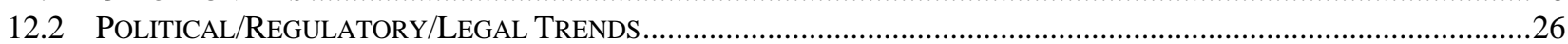

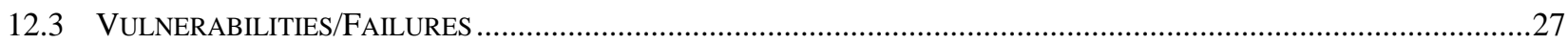

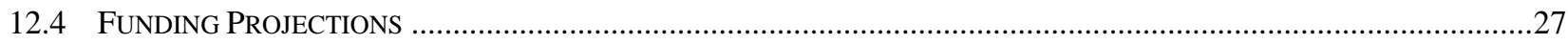

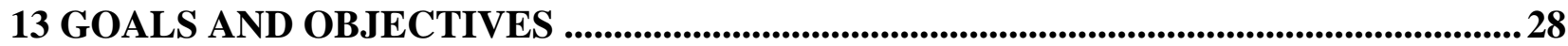

13.1 General ENVIRonmental Management EMS ObJECTIVES AND TARGETS...............................................29

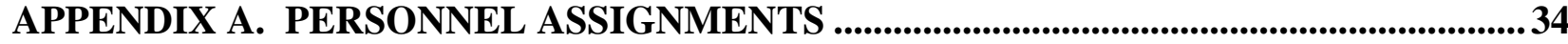

APPENDIX B. HAZARDOUS MATERIALS MANAGEMENT PROGRAM RISK

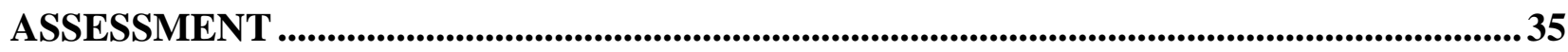

APPENDIX C. HAZARDOUS MATERIALS MANAGEMENT QUALITY SIGNIFICANT PURCHASES DETERMINATION ..........................................................43

APPENDIX D. HAZARDOUS MATERIALS MANAGEMENT PROGRAM SELF

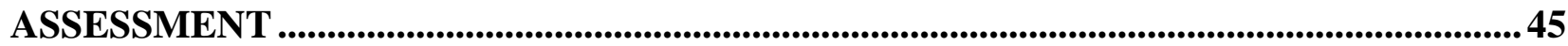

APPENDIX E. HAZARDOUS MATERIALS MANAGEMENT PROGRAM SELF ASSESSMENT DOCUMENT CHECKLIST............................................................................52

\section{Figures}

Figure 7-1. Annual Hazardous Material Inventory Reconciliation “Found” Rate........... 19 Figure 7-2. Annual Hazardous Material Inventory Container Count............................... 20

\section{Tables}

Table 0-1 Summary of Significant Changes to the Hazardous Material Management

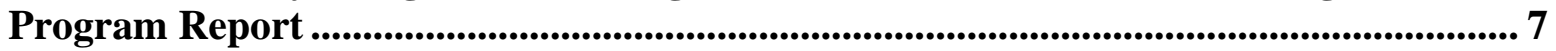

Table 2-1 Compliance Drivers for the Hazardous Material Management Program ........ 10

Table 3-1 Technical Work Documents Applicable to the HMM Program........................... 15

Table 4-1 HMM Program Documents Produced ...................................................................... 15

Table 6-1 HMMP Program Training Matrix ....................................................................... 18

Table 8-1 Hazardous Materials Management Program Risks 2010 ..................................... 23 


\section{Summary of Document Changes}

Significant changes made to this Hazardous Materials Management (HMM) Program Report are summarized in Table 1.

Table 0-1 Summary of Significant Changes to the Hazardous Material Management Program Report

\begin{tabular}{|lll|}
\hline Section & Page & Change \\
\hline 7.2 & 19 & Updated metric data \\
\hline 7.3 & 20 & Updated metric data \\
\hline 12.2 & 25 & Political/Regulatory/Legal Trends updated \\
\hline 13.1 & 28 & EMS Objective \& Targets updated \\
\hline Table 3-1 & 15 & TWD table updated \\
\hline Table 6-1 & 18 & HMMP Training Matrix updated \\
\hline Table 8-1 & 22 & HMMP Risks updated \\
\hline Appendix B & 34 & Risk Assessment Updated \\
\hline Appendix D & 44 & HMMP Self Assessment Report updated \\
\hline Appendix E & 51 & HMMP Assessment Document Checklist updated \\
\hline
\end{tabular}

\section{Program Description}

\subsection{INTRODUCTION}

The HMM Program is one of six programs under the Environmental Management Department at Sandia National Laboratories, California (SNL/CA). The program applies to all projects and activities involving hazardous materials, excluding explosives and radioactive materials, at SNL/CA. The program is part of the corporate HMM Program know as the "Chemical Information System Program” at Sandia National Laboratories/New Mexico (SNL/NM) managed by the Industrial Hygiene Program Department (04127).

SNL/CA is responsible for tracking hazardous materials (chemical and biological hazardous materials), providing Material Safety Data Sheets (MSDS) and for regulatory compliance reporting according to a variety of hazardous material regulations. The principal regulations for hazardous materials tracking are the Emergency Planning Community Right-to-Know Act (EPCRA) and the California Right-to-Know regulations. The regulations, the Hazard Communication/Lab Standard of the Occupational Safety and Health Administration (OSHA) are also key to the HMM Program. The HMM Program is also responsible for supporting hazardous material safety and information requirements for a variety of Integrated Enabling Services (IES) programs primarily the Industrial Hygiene, Waste Management, Fire Protection, Air Quality, Emergency Management, Environmental Monitoring and Pollution Prevention programs. 
The principal program tool is the Chemical Information System (CIS). The system contains two key elements: the MSDS library and the hazardous material container tracking database that is readily accessible to all Members of the Sandia Workforce.

\subsection{Material Safety Data Sheet (MSDS) Library}

The MSDS library in CIS contains over 100,000 MSDSs, which is comprised of commercial MSDS documents and data supplemented with vendor specific MSDS images and data. The MSDS library is available on Sandia's unclassified internal/external web (login required) 24 hours a day, seven days a week with new MSDSs being added as available or by request. The CIS database and ES\&H archives store MSDSs for a period of 75 years according to a DOE epidemiological record destruction moratorium requirement. Manufacturer-specific MSDSs are maintained for products if their MSDS is not available in the commercial library. Just-In-Time (JIT) vendors with contractual chemical tracking requirements are required to provide MSDSs to the HMM Program. Hazardous material users also send MSDSs that accompany their chemical shipments to the HMM Program as outlined in Corporate Policy: ESH100 Environmental Safety \& Health, ESH100.2.IH.20 Maintain an Accurate Chemical and Biological Material Inventory. In addition, the HMM Program request MSDSs from manufacturers as needed or utilize commercially available MSDS library references. MSDSs for new chemical mixtures can be authored in-house by request. The HMM Program processes MSDSs according to internal program procedures.

The web link for access to the MSDS library is: http://cis.sandia.gov

\subsection{Hazardous Material Container Tracking Database}

The CIS database tracks individual hazardous material containers with the use of unique hazardous material inventory barcodes. There are over 33,000 barcoded containers at SNL/CA distributed site-wide managed by nearly every SNL/CA organization. Each individual hazardous material container, as defined by ESH100.2.IH.20 Maintain an Accurate Chemical and Biological Material Inventory is barcoded and all relevant hazardous material inventory information is collected and entered in the CIS database. Information collected includes hazardous material or product name, vendor, storage location, quantity, hazardous material owner/requester information, and container storage information for regulatory reporting purposes.

This electronic inventory allows hazardous material users and Integrated Enabling Services (IES) professionals to assess and manage workplace hazards. CIS data is also key in completing annual federal and state regulatory reporting requirements. Easy access to this inventory facilitates quick availability searches, sharing of chemicals, source reduction, as well as minimizing hazardous material purchases and waste disposal expenses.

Hazardous material tracking in CIS is based on the premise that if the baseline inventory is known and all incoming and outgoing hazardous materials are tracked, the inventory will be upto-date at any given time. All SNL sites complete annual wall-to-wall hazardous materials 
inventory reconciliation. The SNL/CA 2010 reconciliation "found" percent was 95\% compared to $95 \%$ in 2009 and $95 \%$ in 2008.

Just-In-Time (JIT) gas products vendor, Matheson Tri-Gas, barcodes all incoming gas products and forwards the hazardous materials inventory information to the HMM Program electronically. The HMM Program and/or Line hazardous material users are responsible for barcoding all other incoming hazardous materials (non-JIT purchases). Hazardous material users forwards inventory information to the HMM Program using the corporate Chemical Inventory Incoming Form or the "Add Chemical Inventory" on the CIS home page. Hazardous materials users are responsible for storage location changes if a chemical is used, disposed, or transferred to a new location. See ESH100.2.IH.20 Maintain an Accurate Chemical and Biological Material Inventory for responsibilities and procedures for chemical users. Hazardous materials tracking requirements are part of the contract requirements in the JIT vendor contract. The HMM Program processes inventory information according to internal HMM procedures.

\section{Regulatory I Corporate Drivers}

Compliance drivers include laws, regulations, orders, directives and other corporate and sitespecific requirements. The drivers that are applicable to the HMM Program are listed in Table 1.

\subsection{General Compliance}

The HMM Program uses a variety of sources to stay current on applicable compliance drivers. The primary source used is the Sandia corporate notification service provided by the SNL/NM ES\&H Research Librarian. The Research Librarian monitors DOE requirements and federal, state, and local government publications for regulatory issues applicable to Sandia operations. These notifications are then reviewed for applicability to SNL/CA operations. The HMM Program also receives additional sources of information on regulatory changes include direct communication with DOE and regulating agencies, and periodic review of agency web sites. New requirements are incorporated into program activities and communicated to the site through electronic notifications, the ES\&H Interdisciplinary Team process, self-assessments, targeted presentations and program documents.

The HMM Program is audited occasionally by DOE, Sandia Corporation, and Lockheed Martin, Sandia’s parent company. Under California law, Alameda County Department of Environmental Health is required to audit the program every three years.

The HMM Program Lead communicates with DOE/NNSA/SSO (SSO) counterparts regularly to keep them informed of issues and trends of importance to the program. The HMM Program at SNL/CA works closely with our SNL/NM counterparts and DOE/NNSA/SSO to resolve concerns and to develop effective approaches to program implementation. The HMM Program and SSO maintain an open and cooperative relationship. 
Table 2-1 Compliance Drivers for the Hazardous Material Management Program

\begin{tabular}{|c|c|c|}
\hline Driver & Summary & Regulating Authority \\
\hline \multicolumn{3}{|l|}{$\begin{array}{l}\text { Federal Laws and } \\
\text { Regulations }^{\text {a }}\end{array}$} \\
\hline $\begin{array}{l}40 \text { CFR } 300 \text { - } 372 \text { Emergency } \\
\text { Planning Community Right-to- } \\
\text { Know (EPCRA) }\end{array}$ & $\begin{array}{l}\text { The regulations provide for Emergency Planning, } \\
\text { Emergency Notification, Community Right-to-Know } \\
\text { Reporting and Toxic Chemical Release Reporting for } \\
\text { hazardous chemicals at a facility. }\end{array}$ & EPA \\
\hline $\begin{array}{l}29 \text { CFR } 1910.1200 \text { Hazard } \\
\text { Communication Standard } \\
\text { (Worker Right-to-Know Rule) }\end{array}$ & $\begin{array}{l}\text { OSHA's Hazard Communication Standard (HCS) is } \\
\text { designed to ensure that information about these hazards } \\
\text { and associated protective measures is disseminated to } \\
\text { workers and employers. }\end{array}$ & OSHA \\
\hline $\begin{array}{l}29 \text { CFR } 1910.1450 \text { Lab } \\
\text { Standard }\end{array}$ & $\begin{array}{l}\text { The Standard outlines the strategy for laboratories to } \\
\text { maintain employee exposures at or below the } \\
\text { permissible exposure limits specified for the hazardous } \\
\text { chemicals in } 29 \text { CFR part 1910, subpart Z. }\end{array}$ & OSHA \\
\hline $\begin{array}{l}40 \text { CFR } 68 \text { Risk Management } \\
\text { Plan }\end{array}$ & $\begin{array}{l}\text { Section 112(r) of the Clean Air Act focuses on the } \\
\text { efforts to prevent the accidental release of chemicals } \\
\text { and limit the consequenses of such releases. }\end{array}$ & EPA \\
\hline \multicolumn{3}{|l|}{ Executive Orders (EO) } \\
\hline $\begin{array}{l}\text { Executive Order 12856, Federal } \\
\text { Compliance with Right-to- } \\
\text { Know Laws and Pollution } \\
\text { Prevention Requirements }\end{array}$ & $\begin{array}{l}\text { The order directs federal agencies and their facilities to } \\
\text { comply with the provisions of EPCRA and the } \\
\text { Pollution Prevention Act }\end{array}$ & $\begin{array}{l}\text { DOE as responsible } \\
\text { federal agency for } \\
\text { SNL facilities }\end{array}$ \\
\hline $\begin{array}{l}\text { Executive Order } 13423 \\
\text { Strengthening Federal } \\
\text { Environmental, Energy, and } \\
\text { Transportation Management }\end{array}$ & $\begin{array}{l}\text { The order directs federal agencies and their facilities to } \\
\text { a variety of things but the action directly relevant to } \\
\text { HMM program is: Title 3, Section 2, (e) ensure that the } \\
\text { agency (i) reduces the quantiry of toxic and hazardous } \\
\text { chemicals and materials acquired, used, or disposed of } \\
\text { by the agency, (ii) increases diversion of solid waste as } \\
\text { approprite, and (iii) maintains cost-effective waste } \\
\text { prevention and recycling programs in its facilities }\end{array}$ & $\begin{array}{l}\text { DOE as responsible } \\
\text { federal agency for } \\
\text { SNL facilities }\end{array}$ \\
\hline \multicolumn{3}{|l|}{ DOE Directives } \\
\hline $\begin{array}{l}\text { Order 450.1A Environmental } \\
\text { Protection Program / } 2008\end{array}$ & $\begin{array}{l}\text { The order outlines the basic strategy for environmental } \\
\text { compliance at DOE facilities, requires DOE facilities } \\
\text { to implement an EMS that addresses protection of site } \\
\text { resources and long-term stewardship of these resources }\end{array}$ & DOE \\
\hline
\end{tabular}




\begin{tabular}{|l|l|l|}
\hline $\begin{array}{l}\text { Order 151.1C, Emergency } \\
\text { Management / 2005 }\end{array}$ & $\begin{array}{l}\text { The order outlines the basic strategy and requirements } \\
\text { for the Emergency Management Program at DOE } \\
\text { facilities. Emergency Management Hazards Surveys } \\
\text { and Emergency Management Hazards Assessments } \\
\text { (EPHAs) require extensive HMMP support. }\end{array}$ & DOE \\
\hline $\begin{array}{l}\text { California Laws and } \\
\text { Regulations }\end{array}$ & & \\
\hline $\begin{array}{l}\text { State of California, Hazardous } \\
\text { Materials Release Response } \\
\begin{array}{l}\text { Plans and Inventory Law (AB } \\
\text { 2185). }\end{array}\end{array}$ & $\begin{array}{l}\text { California Health and Safety Code requires businesses } \\
\text { to provide information on hazardous substances }\end{array}$ & $\begin{array}{l}\text { Alameda County } \\
\text { Department of } \\
\text { Environmental Health }\end{array}$ \\
\hline
\end{tabular}

${ }^{a}$ The effective date for federal and state regulations represents the most recent revision.

\subsection{Requirements Source Documents}

\section{CFR 300-372 Emergency Planning and Community Right-to-Know Act (EPCRA)}

The Emergency Planning and Community Right-to-Know Act (EPCRA), enacted on October 17, 1986, represents a significant first step toward a major federal role in areas previously regulated by state and local governments. EPCRA was enacted by Congress as a stand-alone provision, Title III, of the Superfund Amendments and Reauthorization Act of 1986 (SARA).

SARA Title III (EPCRA) was passed in response to concerns regarding the environmental and safety hazards posed by the storage and handling of toxic chemicals. These concerns were triggered by the disaster in Bhopal, India, in which more than 2,000 people suffered death or serious injury from the accidental release of methyl isocyanate. To reduce the likelihood of such a disaster in the United States, Congress imposed requirements on both states and regulated facilities. Facilities must notify the local emergency planning districts regarding materials stored at and released from sites.

EPCRA contains three subtitles. Subtitle A, Emergency Planning and Notification, establishes mechanisms to enable states and communities to prepare to respond to unplanned releases of hazardous substances.

Subtitle B, Reporting Requirements, contains three distinct reporting provisions concerning two different groups of chemical substances. The first two sets of reports require submission of inventory-related data on hazardous chemicals [i.e., those substances for which a Material Safety Data Sheet (MSDS) is mandated under the hazard communication regulations of the Occupational Safety and Health Administration]. The third reporting provision requires annual reporting to EPA and the state in which the reporting facility is located on environmental releases of listed toxic chemicals manufactured, processed, or otherwise used at the facility in excess of specified threshold quantities.

Subtitle C, General Provisions, contains a variety of provisions, including, but not limited to, civil, criminal, and administrative penalties for violations of the statute's reporting requirements; 
enforcement actions that can be brought by citizens, states, and emergency planning and response entities; and restrictions on an owner's or operator's rights to make trade secrecy claims in the reports required by EPCRA.

Appendix A of 40 CFR 355 defines extremely hazardous substances. Any DOE facility that manages any such substances in quantities exceeding the Threshold Planning Quantities noted in the appendix must comply with EPCRA.

Under 40 CFR 355 facilities must notify the emergency response commission that they are subject to these requirements. The facilities must notify the local emergency planning unit of releases exceeding a Reportable Quantity (RQ) of Extremely Hazardous Substances, as defined under Title III, and Hazardous Substances, as defined under CERCLA. In addition, the facilities must report their chemical inventories and provide MSDSs to the local emergency planning organizations as outlined in 40 CFR 370.

\section{CFR 1910.1200 Hazard Communication Standard.}

Chemicals pose a wide range of health hazards (such as irritation, sensitization, and carcinogenicity) and physical hazards (such as flammability, corrosion, and reactivity). OSHA's Hazard Communication Standard (HCS) is designed to ensure that information about these hazards and associated protective measures is disseminated to workers and employers. This is accomplished by requiring chemical manufacturers and importers to evaluate the hazards of the chemicals they produce or import, and to provide information about them through labels on shipped containers and more detailed information sheets known as MSDSs. All employers with hazardous chemicals in their workplaces must prepare and implement a written hazard communication program, and must ensure that all containers are labeled, employees are provided access to MSDSs, and an effective training program is conducted for all potentially exposed employees.

\section{CFR 1910.1450 Occupational Exposure to Hazardous Chemicals in Laboratories (Lab Standard).}

The standard entitled "Occupational Exposure to Hazardous Chemicals in Laboratories" (§ 1910.1450; the "Standard") applies to laboratories that use hazardous chemicals in accordance with the Standard's definitions for "laboratory use of hazardous chemicals" (2) and "laboratory scale." (3) The Standard requires these laboratories to maintain employee exposures at or below the permissible exposure limits specified for the hazardous chemicals in 29 CFR part 1910, subpart Z. At SNL/CA this is implemented by the Industrial Hygiene Program in the Corporate Procedure: ESH100.2.IH.4 "Evaluate and Control Chemical Hazards” that describes: Standard operating procedures for using hazardous chemicals; hazard-control techniques; equipmentreliability measures; employee information-and-training programs; conditions under which the employer must approve operations, procedures, and activities before implementation; and medical consultations and examinations. This document also designates personnel responsible for implementing the procedure, and specifies the procedures used to provide additional protection to employees exposed to particularly hazardous chemicals. 
Other information-collection requirements of the Standard include: Documenting exposuremonitoring results; notifying employees in writing of these results; presenting specified information and training to employees; establishing a medical-surveillance program for overexposed employees; providing required information to the physician; obtaining the physician's written opinion; using proper respiratory equipment; and establishing, maintaining, transferring, and disclosing exposure-monitoring and medical records. These collection-ofinformation requirements control employee overexposure to hazardous laboratory chemicals, thereby preventing serious illnesses and death among employees exposed to such chemicals.

\section{Executive Order 12856, Federal Compliance with Right-to-Know Laws and Pollution Prevention Requirements}

Executive Order 12856 published August 6, 1993, 58 FR 41981, directs federal agencies and their facilities to comply with the provisions of EPCRA. Thus, all DOE facilities, including national laboratories, research facilities, power administrations, and petroleum reserves, are potential reporters under EPCRA, if they meet any reporting thresholds.

\section{Executive Order 13423, Strengthening Federal Environmental, Energy, and Transportation Management}

FR Vol. 72, No. 17 published Friday, January 26, 2007 Title 3, Section 2, (e) ensure that the agency (i) reduces the quantity of toxic and hazardous chemicals and materials acquired, used, or disposed of by the agency, (ii) increases diversion of solid waste as appropriate, and (iii) maintains cost-effective waste prevention and recycling programs in its facilities.

\section{State of California, Hazardous Materials Release Response Plans and Inventory Law (AB} 2185).

The California legislature passed Assembly Bill 2185 in 1987, incorporating the provisions of SARA Title III into a state program. The legislature delegated implementation of emergency planning and community-right-to-know programs to the state Office of Emergency Services (OES). OES has in turn authorized local government agencies to implement the program. The Alameda County Department of Environmental Health is responsible for AB 2185 oversight at Sandia/CA.

AB 2185 has been codified in state law as Chapter 6.95 of the California Health and Safety Code. The chapter requires that Sandia/CA complete an annual inventory or "Business Plan" listing specified hazardous materials.

What Chemicals Need to Be Listed On The Inventory? Section 25501.1 of the California Health and Safety Code requires businesses to provide information on all hazardous substances on the federal Environmental Protection Agency (EPA) list at Title 49, Parts 172 and 173 of the Code of Federal Regulations. This list essentially duplicates the class of materials for which a MSDS must be produced. Thus, any chemical for which an MSDS had been produced is considered reportable under Chapter 6.95. Additionally, state law requires that businesses list materials classified as hazardous wastes on the annual inventory. 
Hazardous Materials Management Program Annual Report

\subsection{Implementing Documents}

Corporate Policy: ESH100 Environmental Safety \& Health, ESH100.2.IH.20 Maintain an Accurate Chemical and Biological Material Inventory.

\subsection{Related Documents}

SNL, Chemical Safety Vulnerability Review Management Response Plan, May 27, 1994.

ESH100.2.IH.4 Evaluate and Control Chemical Hazards

ESH100.2.IH.25 Control Chemical Hazards at SNL/CA.

DOE-HDBK-1139/1-2006 September 2006 Chemical Management Volume 1 of 3

DOE-HDBK-1139/2-2006 August 2006 Chemical Management Volume 2 of 3

DOE-HDBK-1139/3-2008 July 2008 Chemical Management Volume 3 of 3 


\section{Operational Controls}

\subsection{HMM Program Operational Controls}

The HMM program uses technical work documents, administrative and engineered controls, and specialized equipment as operational controls. Table 2. lists the technical work documents applicable to the program. They include the corporate ES\&H Corporate Procedures and a Primary Hazards Screening (PHS) document.

The Summer Reconciliation is another operational control implemented to improve the quality of the inventory data and capture information about hazardous materials not encountered in the primary receiving process. Additional information on the reconciliation is found in Section 7.2

\subsection{Additional Operational Controls}

Additional controls are a corporate Just-in-Time purchasing contract with Matheson Tri-Gas for gas products and a Just-in-Time contract for non-gas products with Government Scientific Sources (GSS). In 2010, the SNL/CA contract with GSS was superseded by a corporate Just-inTime contract with GSS on July 1, 2010. Implementation of the new contract at SNL/CA has been difficult due to the lack of clear ownership of the contract implementation at SNL/CA. The implementation has been assigned to Susie Ayers and should be complete in early 2011.

\section{Table 3-1 Technical Work Documents Applicable to the HMM Program}

\begin{tabular}{|l|l|}
\hline Title & Current Version \\
\hline ESH100.2.IH.20 Maintain an Accurate Chemical and Biological & \\
Material Inventory. & $10 / 13 / 2009$ \\
\hline $\begin{array}{l}\text { PHS SNL0A00433 Hazardous Material Management Program at } \\
\text { SNL/CA }\end{array}$ & $9 / 14 / 2010$ \\
\hline AP800003 CIS/HMMP Inventory Procedures at SNL/CA & $11 / 09 / 2010$ \\
\hline
\end{tabular}

\section{Documents Produced}

Table 4-1 HMM Program Documents Produced

\begin{tabular}{|c|c|c|c|c|}
\hline Document & Due Date & $\begin{array}{l}\text { Frequency of } \\
\text { Submittal }\end{array}$ & Distribution & Purpose \\
\hline $\begin{array}{l}\text { EPCRA 302, } 311 \text { and } 312 \\
\text { Reporting }\end{array}$ & March 1 & Annual & $\begin{array}{l}\text { DOE/NNSA/SSO, EPA, } \\
\text { Alameda County CUPA } \\
\text { and Alameda County } \\
\text { Fire Dept. at LLNL }\end{array}$ & $\begin{array}{l}\text { Regulatory } \\
\text { requirement }\end{array}$ \\
\hline $\begin{array}{l}\text { EPCRA } 313 \text { Toxic } \\
\text { Release Inventory (TRI) } \\
\text { Form R } \\
\end{array}$ & July 1 & Annual & $\begin{array}{l}\text { DOE/NNSA/SSO and } \\
\text { EPA }\end{array}$ & $\begin{array}{l}\text { Regulatory } \\
\text { requirement }\end{array}$ \\
\hline California Hazardous & March 1 & Annual & DOE/NNSA/SSO, EPA, & Regulatory \\
\hline
\end{tabular}




\begin{tabular}{|l|l|l|l|l|}
\hline Material Business Plan & & & $\begin{array}{l}\text { Alameda County CUPA } \\
\text { and Alameda County } \\
\text { Fire Dept. at LLNL }\end{array}$ & requirement \\
\hline $\begin{array}{l}\text { Chemicals New To Room } \\
\text { Report }\end{array}$ & NA & Monthly & IH/Medical/HMMP & $\begin{array}{l}\text { IES/Line } \\
\text { Operations }\end{array}$ \\
\hline $\begin{array}{l}\text { Chemicals >= 55 Gallons } \\
\text { Per Storage Room Report }\end{array}$ & NA & Quarterly & HMMP & IES Operations \\
\hline Toxic Gas Report & NA & Quarterly & HMMP & IES Operations \\
\hline Cyanide Report & NA & Quarterly & IH/Medical/HMMP & IES Operations \\
\hline Expiration Date Report & NA & Quarterly & HMMP & IES Operations \\
\hline $\begin{array}{l}\text { EOC Emergency Response } \\
\text { Report }\end{array}$ & NA & Monthly & $\begin{array}{l}\text { Emergency } \\
\text { Management/HMMP }\end{array}$ & IES Operations \\
\hline $\begin{array}{l}\text { SNL/CA Air Quality } \\
\text { Chemical Received Report }\end{array}$ & NA & Monthly & Air Quality/HMMP & IES Operations \\
\hline $\begin{array}{l}\text { SNL/CA Bay Area Toxic } \\
\begin{array}{l}\text { Air Chemical Received } \\
\text { Report }\end{array}\end{array}$ & & & & \\
\hline $\begin{array}{l}\text { SNL/CA Deuterium } \\
\text { Inventory Report }\end{array}$ & NA & Monthly & Air Quality/HMMP & IES Operations \\
\hline $\begin{array}{l}\text { SNL/CA Deuterium } \\
\text { RECEIVED Report }\end{array}$ & NA & Monthly & $\begin{array}{l}\text { SNM Management/ } \\
\text { HMMP }\end{array}$ & IES Operations \\
\hline $\begin{array}{l}\text { SNL/CA Maintenance } \\
\text { Adhesives Disposal Report }\end{array}$ & NA & Monthly & $\begin{array}{l}\text { SNM Management/ } \\
\text { HMMP }\end{array}$ & IES Operations \\
\hline SNL/CA Peroxide Report & NA & Monthly & Air Quality/HMMP & IES Operations \\
\hline $\begin{array}{l}\text { SNL/CA Solvent Disposal } \\
\text { Report }\end{array}$ & NA & Monthly & Air Quality/HMMP & IES Operations \\
\hline $\begin{array}{l}\text { SNL/CA Weekly Disposal } \\
\text { Report }\end{array}$ & NA & Weekly & HMMP & IES Operations \\
\hline $\begin{array}{l}\text { SNL/CA Weekly Purchase } \\
\text { Report }\end{array}$ & NA & Weekly & IH/Security/HMMP & IES Operations \\
\hline
\end{tabular}

\section{$5 \quad$ Approved Job Descriptions / Current Assignments}

\subsection{Program Staffing}

The HMM Program personnel consists of the part-time Program Lead, a full-time HMM Technologist and one Summer Student Interns. A description and associated responsibilities for each position are described below. Current personnel assignments to these positions are found in Appendix A. 


\subsection{Program Lead}

The HMM Program Lead is responsible for managing and overseeing operations, administering permits, reporting requirements and developing special program activities as needed. The program lead also directs the activities of the HMM Technologist who in turn directs the activities of the Student Interns in the program. Primary duties include interpretation of technical/scientific requirements in federal and state laws, regulations, and orders as they apply to hazardous materials management practices; advises management, makes recommendations. Guides the development of hazardous materials management tools and procedures to ensure that these practices are in compliance with the appropriate statutes and regulations, and that regulatory reporting requirements are met. The Program Lead also supports other IES programs on hazardous materials management related activities. In support of these primary duties, the Program Lead sees that Line organizations have knowledge and the tools to effectively manage their hazardous materials. Additional activities include general hazardous material consulation for ES\&H programs and the IES Interdiscplinary Team (IDT). The Program Lead also supports the Emergency Mangement (EM) Hazards Screening/Hazards Assessment Team and serves as the "Chemical Hazards SME" for the EM Program.

\subsection{Program Technologist}

The HMM program efficiently collects and manages hazardous material information for the Line, regulators, DOE, and ES\&H customers. This technologist provides assistance to customers, prepares regulatory compliance reports, performs data, Line and Program quality assurance and manages the Material Safety Data Sheets (MSDS). The HMM Technologist also serves as the lead in the annual chemical reconciliation, supervises student interns, and manages day-to-day operations for the HMM Program. An additional duty includes serving as a back-up Hazardous Waste Technologist in the Waste Management Program.

\subsection{Student Intern}

The Student Intern position has three main components: hazardous material inventory reconciliation and data collection and data entry. Student Interns work under the direct supervision of the HMM Technologist during lab and other field work. During reconciliation they visit every hazardous material storage location and scan the barcodes on the hazardous materials containers, add barcodes and collect all relevant hazardous material data. The computer data entry portion involves entering data collected from the field and entered into the CIS. An additional component of the position entails answering calls from customers, entering information from MSDSs, locating MSDSs, and analyzing and manipulating data. Student Interns must have a positive attitude and good oral and written communication skills. Prior experience in other service organizations is desired but not required. Interns must have experience working in a chemical laboratory environment and must be an independent and selfmotivated worker. Additional required skills include general computer experience and high school chemistry coursework. Must have a GPA greater than 3.2. 


\section{Training and Competency}

Table 6-1 HMMP Program Training Matrix

\begin{tabular}{|c|c|c|c|c|}
\hline Training Requirement & Training Method & 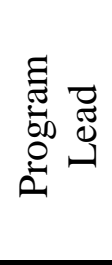 & 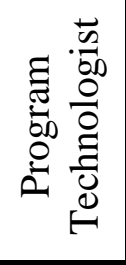 & 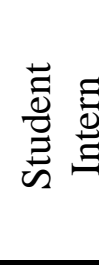 \\
\hline $\begin{array}{l}\text { Advanced degree in chemistry or related } \\
\text { physical/biological science }\end{array}$ & Graduate degree & $\mathrm{O}$ & $\mathrm{N}$ & $\mathrm{N}$ \\
\hline $\begin{array}{l}\text { Bachelor’s degree in chemistry or related } \\
\text { physical/biological science }\end{array}$ & $\begin{array}{c}\text { Bachelor's } \\
\text { degree }\end{array}$ & $\mathrm{R}$ & $\mathrm{O}$ & $\mathrm{N}$ \\
\hline $\begin{array}{l}\text { Associates of Arts/Science degree in chemistry or } \\
\text { related physical/biological science }\end{array}$ & AA/AS degree & $\mathrm{O}$ & $\mathrm{R}$ & $\mathrm{N}$ \\
\hline Hazardous Materials Manager Certification & $\begin{array}{l}\text { HMM Certificate } \\
\text { program }\end{array}$ & $\mathrm{O}$ & $\mathrm{O}$ & $\mathrm{N}$ \\
\hline 40-hr HAZWOPPER certified & $\begin{array}{c}\text { Off-site } \\
\text { classroom }\end{array}$ & $\mathrm{R}$ & $\mathrm{R}$ & $\mathrm{N}$ \\
\hline FRP106 Fire Extinguisher Training Hands-on & SNL classroom & $\mathrm{R}$ & $\mathrm{R}$ & $\mathrm{N}$ \\
\hline $\begin{array}{l}\text { MED104CA Adult CPR and Automated External } \\
\text { Defibrillator for Non-Medical Personnel }\end{array}$ & SNL classroom & $\mathrm{R}$ & $\mathrm{R}$ & $\mathrm{N}$ \\
\hline $\begin{array}{l}\text { MED113 Blood Borne Pathogens Training for } \\
\text { Non-Medical Personnel }\end{array}$ & $\begin{array}{l}\text { SNL classroom } \\
\text { or on-line }\end{array}$ & $\mathrm{R}$ & $\mathrm{R}$ & $\mathrm{N}$ \\
\hline ESH100 ES\&H Awareness & $\begin{array}{l}\text { SNL classroom } \\
\text { or on-line }\end{array}$ & $\mathrm{R}$ & $\mathrm{R}$ & $\mathrm{R}$ \\
\hline CHM100 Chemical Safety Training & $\begin{array}{l}\text { SNL classroom } \\
\text { or on-line }\end{array}$ & $\mathrm{R}$ & $\mathrm{R}$ & $\mathrm{R}$ \\
\hline CHM103 Site Specific Chemical Safety Training & $\begin{array}{l}\text { SNL classroom } \\
\text { or on-line }\end{array}$ & $\mathrm{R}$ & $\mathrm{R}$ & $\mathrm{R}$ \\
\hline $\begin{array}{l}\text { RAD102 General Employee Radiological Training } \\
\text { or RAD230 Radiological Worker Training }\end{array}$ & $\begin{array}{l}\text { SNL classroom } \\
\text { or on-line }\end{array}$ & $\mathrm{R}$ & $\mathrm{R}$ & $\mathrm{R}$ \\
\hline ENV190 Oil Spill Plan Awareness & SNL on-line & $\mathrm{R}$ & $\mathrm{R}$ & $\mathrm{N}$ \\
\hline $\begin{array}{l}\text { ENV191 Annual Site Specific Discharge } \\
\text { Prevention Briefing }\end{array}$ & SNL classroom & $\mathrm{R}$ & $\mathrm{R}$ & $\mathrm{N}$ \\
\hline
\end{tabular}

$\mathrm{R}=$ required, $\mathrm{O}=$ Optional, $\mathrm{N}=$ Not Required 


\section{Performance Measures}

\subsection{Regulatory Reporting}

Regulatory reporting will be completed as prescribed in Table 4-1 HMM Program Documents Produced.

\subsection{Annual Hazardous Material Inventory Reconciliation "Found" rate}

The annual hazardous material inventory reconciliation "found" rate performance target is greater than or equal to 90\%. In 2010, the HMM Program matched the highest reconciliation "found rate" of 95\% in the over fifteen years the HMM Program has been doing an annual hazardous material inventory reconciliation. This exceeds the corporate performance target (90\%). Figure 7-1. illustrates the "found" rate performance over the last decade and shows steady progress toward a rate consistently in the low $90 \%$ range. Although improvement is desired, additional resources are needed (or redirecting existing resources) to increase Line education, increase data surveillance and improve site business processes to achieve improved results.

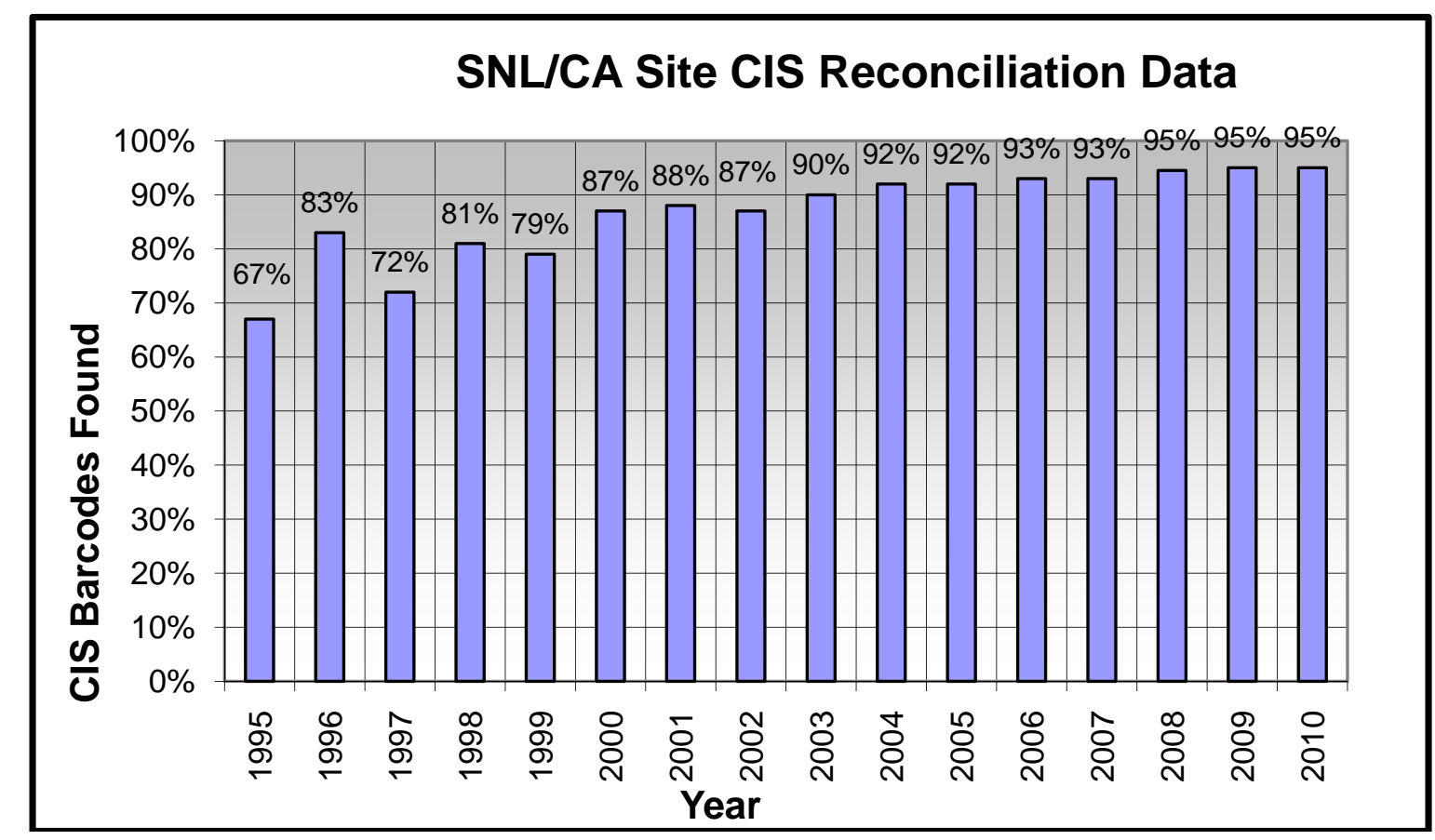

Figure 7-1. Annual Hazardous Material Inventory Reconciliation “Found” Rate. 


\subsection{Annual Hazardous Material Inventory Container Count}

Figure 7-2. illustrates the total site hazardous material container count and the site container count of NFPA Health 3 \& 4 rated materials. The general trend observed from the first site inventory in 1994 until 2002 was the increasing of the total container count. Some of the increase was due to the improvement of the inventory process to account for more containers but the majority of the increase was likely due to the implementation of the Waste Management chargeback. The chargeback process requires waste generators to directly pay a portion of the cost of disposal in an effort to encourage waste minimization. The chargeback likely resulted in excessive inventories as generators avoided disposal costs and waste generation by keeping unnecessary material in inventory. Thus, the chargeback works as a disincentive to reduce hazardous material inventory, essentially deferring waste disposal and requiring periodic campaigns to "right size" the hazardous material inventory.

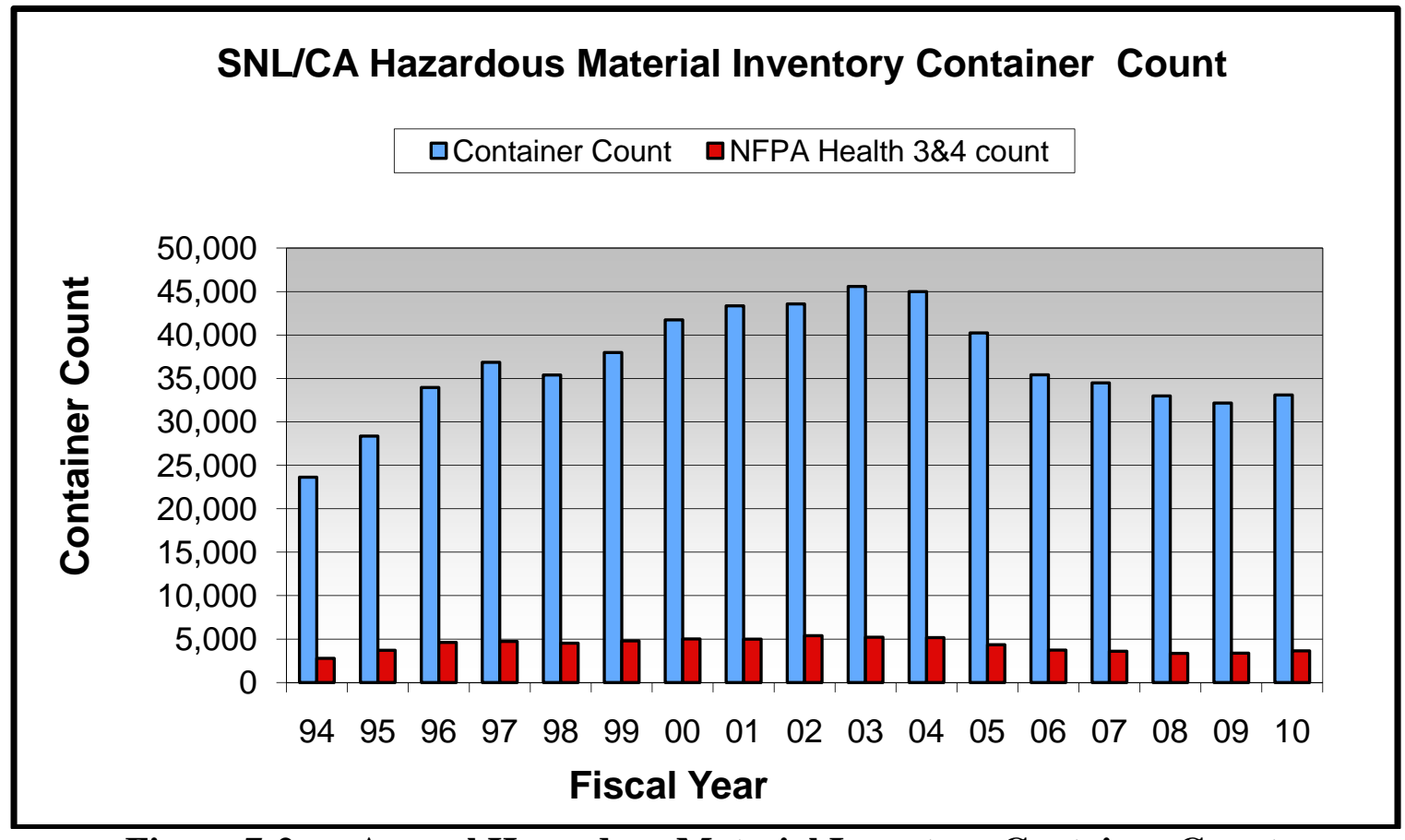

Figure 7-2. $\quad$ Annual Hazardous Material Inventory Container Count 


\section{Quality Assurance}

\subsection{Data and Reporting Quality Assurance}

The HMM Program applies the following program-specific elements to assure quality is maintained in data collection, analyses, and reporting.

- Online and hardcopy validation tools, screens and forms ensure that a standard process is followed for collection and management of inventory data.

- All data input is reviewed for accuracy after the input is complete.

- All regulatory lists are periodically reviewed and updated.

- Internal reports and documents are subjected to internal review and technical editing before finalizing.

- DOE/SSO, applicable SNL/CA staff and technical editor's review published reports before finalizing.

\subsection{Annual Hazardous Material Inventory Reconciliation}

Summer reconciliation is a quality assurance process where a team of Student Interns is led by the HMM technologist.

- The reconciliation uses portable barcode readers to find all barcoded containers on-site.

- Reconciliation results are e-mailed to the location owners for verification.

- Location ownership is verified with the annual reconciliation.

\subsection{Additional Assurance Activities}

- Requested ad hoc reconciliations/transfers of hazardous material inventory are performed to assure data quality.

- Ad Hoc e-mail notification is provided to inform the resigning, retiring, or terminated employee's manager that that person was or has been responsible for specific locations and/or hazardous materials. This ensures that the ownership of inventory is up-to-date.

\subsection{Program Risk Assessment}

In January 2011, the HMM Program updated a risk assessment (Appendix B) as part of the decision making process to determine the appropriate level of formality required for Program activities and identified seven potential risks related to program activities. Table 6 lists each risk and the calculated risk category. The overall risk for HMM Program issues were determined to be medium. Measures taken by the HMM Program to mitigate this risk are 1) routine HMM personnel training, 2) maintaining operational controls, 3) improve processes and systems (CIS) and 4) Line training. 
Hazardous Materials Management Program Annual Report

February 2011

Page 22 of 53 
Table 8-1 Hazardous Materials Management Program Risks 2010

\begin{tabular}{|c|l|l|}
\hline Risk \# & Risk & $\begin{array}{l}\text { Overall Risk } \\
\text { Category }\end{array}$ \\
\hline 1 & Hazardous materials not being tracked in CIS & low \\
\hline 2 & Aging chemicals or containers & medium \\
\hline 3 & Hazardous materials misidentified in CIS & low \\
\hline 4 & Storage incompatibility & medium \\
\hline 5 & Excess inventory & medium \\
\hline 6 & Site-wide Earthquake Induced Spill or Accident & low \\
\hline 7 & Reduction of program funding by 10\% & high \\
\hline 8 & Regulatory Noncompliance & low \\
\hline
\end{tabular}

For the low risk category for Risk 1, the hazardous materials not being tracked are usually the result of local procurement and site personnel not obtaining a barcode for the container. The risk is minimized by the summer inventory reconciliation, additional Line training of their barcoding responsibilities and tighter procurement controls restricting local purchasing.

In response to the medium risk category for Risk 2, the risk is minimized by the inventory reduction campaigns and targeted chemical safety surveillance of the peroxidizable/autopolymerizable materials.

For the low risk category for Risk 3, updating incorrect data as it is observed minimizes the risk.

For the medium risk category for Risk 4, correcting problems observed during a variety of Line assessment processes minimizes the risk.

For the medium risk category for Risk 5, the risk mitigation is addressed by an explicit annual EMS goal.

For the low risk category for Risk 6, the risk is minimized by correcting problems observed during a variety of Line assessment processes and through inventory reduction.

For the high risk category for Risk 7, the risk is minimized by a review of program activities that could be streamlined. A 10\% reduction in program funding would result in decreased staffing, training, and purchases. Only those program activities that are required by regulation, Sandia policy, technical work documents, or DOE/NNSA would be conducted. Discretionary training and travel for program staff would be eliminated. Purchases for replacement equipment and equipment repair would be reduced. A reduction in Line training and support would occur.

For the low risk category for Risk 8, the Fire Protection Program was identified during the Fall 2008 Alameda County Department of Environmental Health (SNL/CA CUPA) Assessment to be under managing hazardous materials according to the California Fire Code (CFC). A similar situation exists with the International Fire Code (IFC) that is regulated by DOE. This situation has been improved by report modifications in CIS. Full CFC compliance, however, is difficult 
without comprehensive hazard categorization data that is not available for all the hazardous materials on site. This identified risk is dependent on the extent the CUPA chooses to regulate the CFC at SNL/CA. All California facilities struggle with these regulations and full compliance

\subsection{Quality Significant Purchases Determination}

A Quality Significant Purchases Determination, Appendix C, has been completed in accordance with the Environmental Management Quality Assurance Program Plan. The HMM Program does not have any quality significant items.

\section{Program Assessments}

\subsection{Follow-up on the 2009 Program Self-Assessment}

The 2009 Program Self Assessment identified issues with Line under-compliance with requirements and HMM Program documents out-of-date. The FY2010 Program Self Assessment showed considerable improvement in up-to-date documentation. Line under-compliance in the HMM program area has improved as well. With little mention of HMM problems in EP Rep. Assessments and site Management Self Assessments.

\subsection{FY 2010 Program Self-Assessment}

The FY 2010 HMM program self-assessment was completed in December 2010. The program self-assessment is included in Appendix D. The chemical and biomaterial procurement and the delivery of these products is a concern that was focused on the FY 2010 Program SelfAssessment. During this assessment, a review of the chemical receiving SNL/CA joint operations with LLNL and supply chain process was completed. With the initial consolidation of joint operations, problems rose in the chemical receiving operations. Since then CIS/HMMP and Logistics have worked jointly to resolve these issues and come up with alternative solutions. However, one remaining issue lies with the separation of logistics and chemical receiving operations that has lead to a breakdown in communication between the two groups. Once the new corporate JIT contract is fully implemented at SNL/CA, we hope that it will improve the chemical receiving process and resolve any remaining issues.

Improvements to these processes are expected in FY2011 led by Susie Ayers.

\subsection{Line Performance Assessment}

The FY2010 Program Self Assessment did not focus on the Line but included information about procurement and logistics experienced by the Line user. This information is found in section 9.2 FY 2010 Program Self-Assessment and in Appendix D. 


\subsection{Environmental Programs Representative Assessment}

The year-round Environmental Programs Representative (EP Rep.) assessment led by the Division 8000 EP Rep. at Sandia/CA, Deanna Dicker, reports issues to the Hazardous Material Management Program Lead. If necessary, Line Self-Assessment findings are issues. See section 9.5 for the findings HMM program findings issued since they are not reported separately.

\subsection{Corporate Line Self Assessment}

The year-round corporate Line self assessment team led by the 8000 Division ES\&H Coordinator at Sandia/CA issued 5 HMM program related findings for missing barcodes on hazardous material containers. These findings were all resolved by barcoding the containers soon after the findings were issued. Missing barcodes are typically the result of items purchased and brought on-site by the Line and the owner fails to notify the HMMP that the item needs barcoding.

\section{Accomplishments}

\subsection{System Upgrades}

The HMM Program continues to actively update or enhance the CIS as needed. Minor upgrades were acomplished in several software releases during 2010. However, no major upgrade to CIS was released this year.

\subsection{Inventory Reconciliation}

The HMM Program performs an annual hazardous material inventory reconciliation during the Summer months. In 2010, the HMM program team equaled the highest "found rate" with a 95\% rate. This exceeds the corporate performance target (90\%). Hazardous material inventory process improvements, part of other goals, should result in a gradual improvement in the "found rate". Therefore, no specific tasks are proposed to increase the "found rate" and the performance target (90\%) remained the same in 2010.

\subsection{Inventory Reduction}

In FY2010, no inventory reduction campaign was done. However, building 968 personnel did do a cleanup of some of their chemical storage areas with the help of the Hazardous Materials Management and the Waste Management Program personnel. In late FY2011, another inventory reduction compaign is anticipated due to the underrecovery of the Waste Management program.

\subsection{Emergency Management - Hazards Survey \& EPHA}

A Hazards Survey compliant with DOE O 151.1C was conducted by AlphaTRAC for the SNL/CA Emergency Management Program during the summer of 2008. This effort was supported by the HMM Program through site tours and data reviews. The Hazards Survey indicated the only two area of concern that require Emergency Planning Hazards Assessments 
(EPHAs) are 961/9611 and 968 to further assess the hazards of concern to the Emergency Management Program. In 2010, the HMM program continued to support the Emergency Planning Hazards Assessments lead by the Emergency Management Program.

\section{Issues}

\subsection{Line Housekeeping Issues}

The most significant program issue continues to fall in the general category of Line chemical storage housekeeping. General housekeeping issues continue to be the focus in the DOE initiative started several years ago on Unneeded Materials and Chemicals. At SNL/CA, some Line chemical storage locations are kept in good condition. However, some are neglected and overstocked with unneeded and often unusable materials. Some of the neglected locations also include hazards such as Black Widow spiders, rodent feces and excess equipment that add significant personnel safety issues and operational inefficiencies.

\section{Trends}

\subsection{Opportunities}

The HMM Program's greatest advancement opportunity came from the implementation of the modernized CIS software. In 12/2004 the team introduced a robust set of tools in the new CIS software that allow for much greater effectiveness in the management of the hazardous material inventory. These tools also provide an unprecedented opportunity to gather information about the inventory. This information can be used principally by the ES\&H Subject Matter Experts (SMEs) to manage their programs more effectively. One example of this is the Emergency Planning Community Right-to-Know Toxic Release Inventory (TRI) reporting. The CIS can provide information so effectively that the effort to prepare the TRI report is extensively reduced saving tens of thousands of dollars per year. Hazards assessments can also be done in a fraction of time saving resources. The Line can more effectively access their inventory and associated material safety data to minimize purchasing and waste disposal costs while reducing personnel potential exposure to hazardous chemicals. To take advantage of these opportunities addition training needs to be provided to the Line and ES\&H SMEs. Only when personnel see the tools available to them will they begin to take advantage of the innovation inherent in the new CIS. The CIS continues to be upgraded with additional features and bug fixes.

\subsection{Political/Regulatory/Legal Trends}

Prior to 9/11/2001, hazardous material inventories were considered necessary for operations and regulatory reporting. However, post 9/11/2001, there has been a renewed interest in the importance of hazardous material inventories especially from the risk of hazardous material related terrorism. The concern of misused hazardous materials also is focused on drug and drug precursor materials with new regulations complicating the purchasing process of some materials. 
The DOE is especially concerned in the area of Hazards Surveys and Hazards Assessments for Emergency Management programs and the health effects of hazardous materials such as beryllium and NFPA Health 3 and 4 rated material. DOE at various levels from DOE HQ to DOE/NNSA/SSO have begun to raise the concern that chemical management throughout the DOE complex needs to be improved to meet operational needs and Emergency Management planning requirements. Sandia is addressing these concerns through an Issues Management Team at SNL/NM focused on chemical management. This resulted in a variety of improvements to CIS in the last several years.

Since 2008, the Alameda County Department of Environmental Health, also know as the Certified Unified Program Agency (CUPA) with jurisdiction over SNL/CA, has stepped up auditing at the site. This has resulted in a Hazardous Material Business Plan change in the form of an addition of a hazardous waste tank not previously included. It was not included previously because it was believed to only contain non-hazardous process wastewater. This change was required as part of a Notice of Violation issued in August 2010. Other CUPA driven changes have also occurred but they are out of the scope of the Hazardous Materials Management Program.

\subsection{Vulnerabilities/Failures}

The success of hazardous material inventory management at SNL/CA depends on hundreds of personnel performing a variety of tasks to maintain the required accuracy of the information. This is an ongoing struggle because inventory management is not the primary activity of Line personnel. Hazardous materials that are consumer commodities are routinely purchased from local stores and brought on-site. Since these items do not go through receiving, the Line is required to notify the HMM program for barcoding service. The Line frequently fails to notify the HMM program when they purchase these items, however, the containers are barcoded when they are found in the summer reconciliation. Ongoing effective training and monitoring of the data is required to maintain the desired data quality objectives of the information. A variety of improvements to CIS were implemented in the last several years addressing some of these vulnerabilities and system failures and better inventory accuracy in 2009 and 2010 suggests that these changes were effective.

\subsection{Funding Projections}

ES\&H general funding projections for FY 2011 are for zero baseline increase and zero increase for inflation. As labor costs increase, a shortfall is likely. The HMM program has no independent budget but is funded by a matrix of funding sources with primary funding coming from the Industrial Hygiene budget ( 1.25 FTE). Significant secondary funding comes from the Waste Management Program ( 0.25 FTE). Additional minor funding (0.1 FTE) is provided from the SNL/NM CIS Program for technical support.

No significant purchases are required apart from minor desktop software upgrades for Calendar Year 2011. Travel and training costs are usually minimal at $<\$ 6,000$ per year. 
The Alameda County Department of Environmental Health, the site Certified Unified Program Agency (CUPA), annually bills Sandia $\sim \$ 35,000$ on or about July 1 . This fee is based on the amount of hazardous materials reported on the Business Plan submitted by SNL/CA in the preceding February. The funds for this bill have come from the HMM portion of the Industrial Hygiene budget.

\section{Goals and Objectives}

The HMM Program is subject to internal goals and objectives established by Sandia's Integrated Enabling Services Strategic Management Unit and by SNL/CA’s EMS Program.

The primary goal of the HMM Program is to ensure safe and effective hazardous materials inventory management at Sandia/CA. This is done by efficiently collecting and managing hazardous material information for our customers who include Line, regulators, DOE and ES\&H programs to ensure compliance with regulations and to streamline customer business processes that require hazardous material information. 


\subsection{General Environmental Management EMS Objectives and Targets FY2011 SNL/CA Environmental Objectives}

(Recommended by EMS Core Team on: 12/23/2010)

1. Demonstrate exceptional environmental performance and management.

2. Minimize consumption (energy, water, non-renewable resources).

3. Minimize the production of waste (non-hazardous, hazardous, radiological, wastewater).

4. Minimize air pollutant and green house gas emissions.

5. Preserve and, when possible, enhance the site's natural habitat.

6. Design and manage all buildings and facilities using "green" principles.

7. Maintain sewer effluent within regulatory discharge limits.

8. Minimize the volume and pollution of storm water runoff.

9. Procure and use environmentally friendly products and materials.

10. Minimize pollutants released to the ground or ground water (spills, landscape chemicals, metals, etc.).

Approved:

Rick Stulen, VP 8000

Date 


\section{FY2011 SNL/CA Environmental Targets}

(From the SNL FY2010 Site Sustainability Plan approved on 12/14/10)

(Approved by SSHEAC on Dec 2, 2010)

Corporate 1: By FY15, reduce energy intensity by 30 percent. (FY03 Baseline)

Corporate 2: By FY20, reduce Scope 1 and Scope 2 Green House Gas emissions by 28 percent. (FY08 Baseline)

Corporate 3: By FY20, reduce scope 3 GHG emissions by 13 percent. (FY08 Baseline)

Corporate 4: By FY20, reduce water intensity by 26 percent. (FY07 Baseline)

Corporate 5: By FY20, reduce the use of petroleum (diesel, gasoline and 15\% E85) by 30 percent. (FY05 Baseline)

Corporate 6: By FY15, increase fleet alternative fuel consumption by 10 percent per year. (FY05 Baseline)

Corporate 7: By FY12, divert at least 65 percent of non-hazardous solid waste, excluding construction and demolition debris.

Corporate 8: To the maximum extent practical install advanced metering for electricity (by Oct 2012), steam and natural gas (by Oct 2015) and standard meters for water.

Corporate 9: Achieve LEED Gold for all new construction $>\$ 5 \mathrm{M}$ and HPSB principles for projects $<\$ 5$.

SNL/CA Specific: None for FY11.

Approved:

Rick Stulen, VP 8000

Date 


\section{FY2011 SNL/CA Environmental Actions (Means)}

(Recommended by EMS Core Team: Jan 3, 2011)

(Approved by 8510 Sr. Mgmt on: Jan 5, 2011)

Objective: Demonstrate exceptional environmental performance and management.

Action 1: Maintain ISO14001 certification of SNL/CA's Environmental Management System.

Action 2: Implementation CA elements of the SNL FY2010 Site Sustainability Plan and other environmental plans, order, etc, as required.

Action 3: Brief CA management (Tri-Level) on sustainability, energy and the Corporate/CA plans.

Objective: Minimize consumption (energy, water, non-renewable resources). Action 4: Re-lamp and ballast change from T12 to T5 in Buildings 905/906.

Action 5: Provide for modifications to the EMS software and some new hardware deployment.

Action 6: Continued installation of the "Dolphin" water treatment units on all major towers to reduce blowdown.

Objective: Minimize the production of waste (non-hazardous, hazardous, radiological, wastewater).

Action 7: Track down and eliminate if possible the source of increased wastewater coming into the B916 LEC.

Action 8: Maintain an annual overall Chemical Information System reconciliation of $>95 \%$.

Action 9: Maintain an annual Chemical Information System reconciliation of $100 \%$ for the NFPA 704 health hazard rated 4 materials greater than $10 \%$ of laboratory scale quantities (4 lbs solid, 0.5 gal liquid, $1 \mathrm{lb}$ gas).

Objective: Minimize air pollutant and green hours gas emissions. 
Action 10: Complete the installation of two new CA compliant hot water boilers ASAP, three additional boilers by $12 / 31 / 2011$ and the final two new boilers by $12 / 31 / 201$ to remain compliant with BAAQMD regulations 9-7-307.

Action 11: Curtail fueling operations as much as possible on BAAQMD declared Spare-The-Air-Days.

Action 12: Reduce the number of site 1301 Halon system and extinguishers and convert if needed to green fire suppressant.

Objective: Preserve and, when possible, enhance the site's natural habitat. Action 13: Implement the most critical actions identified in the Arroyo Seco Management Plan within 10 years of receipt of the 10 year permit (Permit received Sept 25, 2008).

Action 14: Maintain the plantings in the Arroyo Seco to support the Management Plan and permit conditions.

Objective: Design and manage all buildings and facilities using "green" principles.

Action 15: Obtain LEED NC rating for B903.

Action 16: Transition landscaping to xeriscaping as every opportunity arises.

Objective: Maintain sewer effluent within regulatory discharge limits. Action 17: Complete the FY11 specified facilities-funded sewer piping system improvements.

Action 18: Complete the facilities-funded sewer monitoring station modifications and perform all the additional required sampling/analysis required by the City until the site can return to normal compliance.

Action 19: Conduct complete pressurized sewer line cleaning annually. (next Aug 2011). 
Action 20: Conduct CCTV inspection of all sewer lines 6 inches and greater at least every three years. (next July 2013)

Action 21: Conduct site sump cleaning every three years (next Jan 2011).

Action 22: Conduct study of the chemistry taking place of a select branch line for during low or no flow conditions

Objective: Minimize the volume and pollution of storm water runoff and other water discharges.

Action 23: Obtain in-house staff certification as a SWPPP storm water plan developer and approver by Sept 30, 2011.

Action 24: Perform 100\% inspection/cleaning of streets/gutters and other storm drain system structures by Oct 15 of each year.

Objective: Procure and use environmentally friendly products and materials. No specific actions

Objective: Minimize pollutants released to the ground or ground water (spills, landscape chemicals, metals, etc..

No specific actions.

Approved:

John Garcia, Sr. Mgr. 8510

Date 
Hazardous Materials Management Program Annual Report

\section{Appendix A. Personnel Assignments}

\begin{tabular}{lll}
\hline Job Assignment & Personnel & Back-Up \\
\hline Program Lead & Mark Brynildson & Robert Holland/Randy Castillo \\
\hline Program Technologist & Susie Ayers & Pam Irish \\
\hline Student Intern & None assigned & None assigned \\
\hline
\end{tabular}




\section{Appendix B. Hazardous Materials Management Program Risk Assessment}

\section{Hazardous Materials Management Program Risk Assessment (FY2011)}

The risk assessment process for the Hazardous Materials Management Program follows the general steps of

1. Identify the risk

2. Identify the probability of the event occurring

3. Identify the consequence if the event occurs.

The following tables will be used to assign a numeric value to the probabilities and consequence categories.

\begin{tabular}{|c|l|}
\hline $\begin{array}{c}\text { Likelihood/Probability } \\
\text { Of Occurrence Level }\end{array}$ & Likelihood/Probability Criteria \\
\hline Very High & $\bullet$ Everything points to this occurring \\
\hline High & $\begin{array}{l}\bullet \text { High chance - Lack of relevant processes or experience contribute to a } \\
\text { high chance of occurrence }\end{array}$ \\
\hline Medium & $\bullet$ Even chance of occurrence \\
\hline Low & $\bullet$ Not much of a chance of occurrence \\
\hline Negligible & $\bullet$ Negligible chance this will occur \\
\hline
\end{tabular}

\begin{tabular}{|c|c|}
\hline $\begin{array}{l}\text { CONSEQUENCEI } \\
\text { SEVERITY LEVEL }\end{array}$ & CONSEQUENCE/SEVERITY CRITERIA \\
\hline High & $\begin{array}{l}\text { damage (e.g., ozone depletion, rad soil contamination) } \bullet \text { Serious } \\
\text { environmental impact resulting in recovery actions lasting } 5 \text { years or } \\
\text { more (e.g., TCE in aquifer) } \bullet \text { Results in General Emergency (affects both } \\
\text { onsite and offsite) } • \text { Unsatisfactory rating by external regulators or cease } \\
\text { and desist order } \cdot \text { Affects lab leadership, including prime contract } \bullet \\
\text { Actions, inactions or events that pose the most serious threats to } \\
\text { national security interests and/or critical DOE assets, create serious } \\
\text { security situations, or could result in deaths in the workforce or general } \\
\text { public (i.e., IMI-1) } 1 \cdot \text { Actions, inactions or events that pose threats to } \\
\text { national security interests and/or critical DOE assets or that potentially } \\
\text { create dangerous situations (i.e., IMI- } 2)+\cdot \text { Unallowable costs or fines } \\
>\$ 1 M \cdot \text { Adverse public opinion }- \text { high interest/widespread open public } \\
\text { attention or debate (lasting weeks to months) } \cdot \text { Customer dissatisfaction } \\
\text { results in permanent loss of lab customer } \bullet \text { Catastrophic failure to meet } \\
\text { internal requirements } \cdot \text { Loss of major program within the division } \\
(>\$ 10 \mathrm{M})\end{array}$ \\
\hline
\end{tabular}




\begin{tabular}{|c|c|}
\hline Medium & 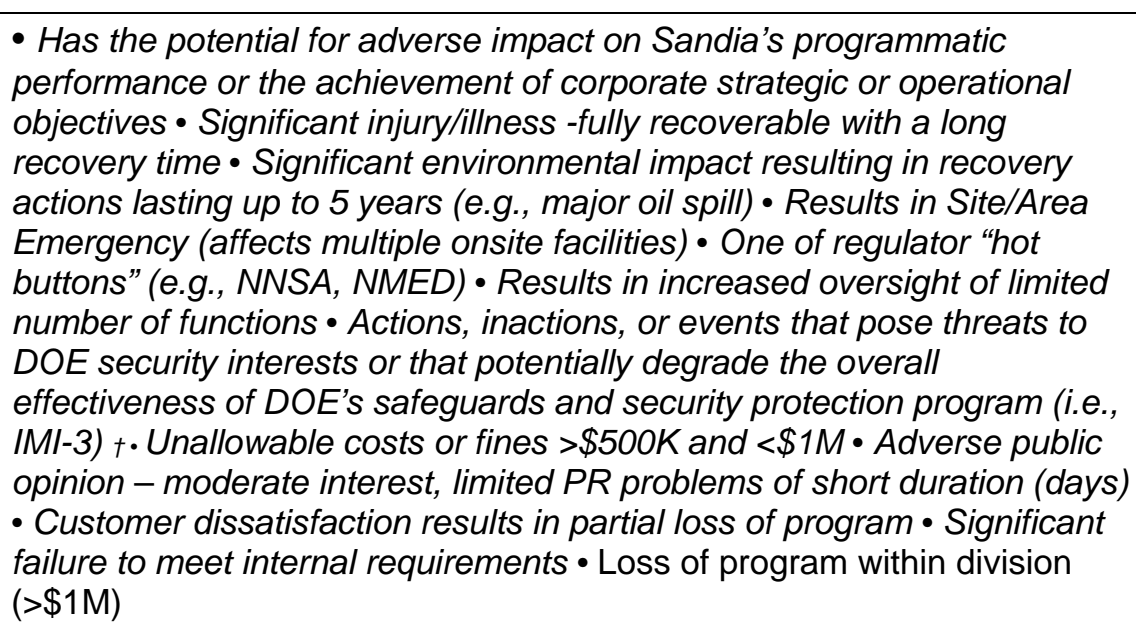 \\
\hline Low & $\begin{array}{l}\text { - Minimal injury/illness - Fully recoverable with a short recovery time } \bullet \\
\text { Minimal environmental impact that can be improved within days } \bullet \\
\text { Results in increased short-term oversight } \bullet \text { Results in an Operational } \\
\text { Emergency (affects a single onsite facility) } \bullet \text { Actions, inactions, or events } \\
\text { that could pose threats to DOE by adversely impacting the ability of } \\
\text { organizations to protect DOE safeguards and security interests (i.e., IMI- } \\
4)+\cdot \text { Unallowable costs or fines }<\$ 500 \mathrm{~K} \cdot \text { Adverse public opinion with } \\
\text { short-term local negative publicity or embarrassment }\end{array}$ \\
\hline Negligible & - Little or no attention, might be discussed as lesson learned \\
\hline
\end{tabular}

The risk level will be graded according to the following matrix. Adapted from DOE O 471.4.

\begin{tabular}{|c|c|c|c|c|c|}
\hline & \multicolumn{5}{|c|}{ RISK GRADING LEVELS } \\
\hline & & \multicolumn{3}{|c|}{ Consequence/Severity } & \multirow[b]{2}{*}{ High } \\
\hline & & Negligible & Low & Medium & \\
\hline \multirow{5}{*}{$\begin{array}{l}\text { Likelihood } \\
\text { of } \\
\text { Occurrence }\end{array}$} & Very High & Low & Medium & High & High \\
\hline & High & Low & Medium & High & High \\
\hline & Medium & Low & Medium & Medium & High \\
\hline & Low & Low & Low & Low & Medium \\
\hline & Negligible & Low & Low & Low & Low \\
\hline
\end{tabular}




\section{Identified Risks Associated with the Hazardous Materials Management Program}

1. Hazardous materials not being tracked in CIS

2. Aging chemicals or containers

3. Hazardous materials misidentified in CIS

4. Storage compatibility

5. Excess Inventory

6. Site-wide Earthquake Induced Spill or Accident

7. Reduction in Program Funding by $10 \%$

8. Regulatory Noncompliance

\section{Hazardous materials not being tracked in CIS}

\section{a. Identification of Risk}

There are two methods whereby hazardous materials may come on-site and not be entered into the CIS database. These are 1) hazardous materials are purchased off-site and hand-carried on-site by the purchaser, and 2) hazardous materials arriving at shipping and receiving are not clearly marked as such, and are thus delivered directly to the customer's location.

\section{b. Probability of Occurrence}

The probability is low for high risk items (higher hazard), since these items can not usually be purchased at local retailers. Higher hazard items are also usually clearly identified on shipping containers. The probability for low hazard materials is fairly significant, since not all members of the workforce are aware of the universe of materials tracked by CIS. Therefore, the overall probability is graded as LOW.

\section{c. Consequence of Occurrence}

If materials are not included in CIS, it is possible that they will be stored in areas not authorized for that material. Another risk is the exceedance of the safety envelop for a specific location. This could result in a change to emergency response protocols for that facility. The consequence is graded as LOW.

\section{d. Overall Risk Category}

In accordance with the chart above, for a risk with a probability of LOW with a LOW consequence, the risk category is LOW. 


\section{Aging chemicals or containers}

\section{a. Identification of Risk}

Some chemicals become unstable with age. Examples are chemicals such as ethers that for explosive peroxides with aging.

Certain chemical containers deteriorate with age, causing a spill hazard.

\section{b. Probability of Occurrence}

The Hazardous Materials Management Program tracks the age of chemicals that form explosive compounds with age. Notices are sent to owners reminding them to remove such chemicals before they become a hazard. Approximately 20 containers per year are dealt with in this fashion.

Deteriorating containers are minimized through the efforts of the Hazardous Materials Management Program to minimize old, unused chemicals on-site.

These processes are partially manual, in that although the CIS can generate reports on age of chemicals, Hazardous Materials Management Program personnel must then manually send notices to the owners.

The probability of this risk is graded as MEDIUM.

\section{c. Consequence of Occurrence}

Aging chemicals pose a potential explosion or spill hazard. Consequences of an explosion or spill are mitigated by the fact that only small containers are typically purchased, and that they are stored in appropriate locations. The consequence is graded as LOW.

\section{d. Overall Risk Category}

In accordance with the chart above, for a risk with a probability of MEDIUM and a LOW consequence, the risk category is MEDIUM.

\section{Hazardous materials misidentified in CIS}

\section{a. Identification of Risk}

Chemicals are occasionally found to be misidentified in CIS. Usually the misidentification occurs when the CIS bar-code label is attached to the chemical bottle (e.g. the bar code label for a different bottle is accidentally attached). 


\section{b. Probability of Occurrence}

A few containers per year are found to be misidentified, therefore the probability is graded as LOW.

\section{c. Consequence of Occurrence}

Misidentification in CIS does not imply that the user is not aware of the true identity of the chemical. However, the CIS database will be incorrect until the item is caught and corrected. This can lead to improper storage or the exceedance of safety envelopes, as noted above in item 1.

The consequence of this is graded as LOW.

\section{d. Overall Risk Category}

In accordance with the chart above, for a risk with a probability of LOW and a LOW consequence, the risk category is LOW.

\section{Storage incompatibility}

\section{a. Identification of Risk}

Given the large number of chemicals on-site, there is a risk of incompatible chemicals being stored in proximity to each other.

\section{b. Probability of Occurrence}

During the reconciliation process, it has been determined that although most chemicals on-site are stored properly, a few problems can be found in most areas where large numbers of chemicals are stored. The probability is graded as MEDUIM.

\section{c. Consequence of Occurrence}

Only small quantities of the most hazardous materials are purchased and stored. Storage within chemical sheds, or other types of secondary containment serves to minimize the amount of incompatible materials subject to mixing. The consequence is graded as LOW.

\section{d. Overall Risk Category}

In accordance with the chart above, for a risk with a probability of MEDIUM and a LOW consequence, the risk category is MEDIUM.

\section{Excess Inventory}

\section{a. Identification of Risk}


If the inventory of certain hazardous materials exceeds a regulatory threshold, SNL/CA would be required to prepare and implement an Emergency Management Program. Also, excess inventory poses an increased risk during an accidental release to personnel and the environment. Periodic surveillance of the inventory for chemical safety concerns such as explosive forming peroxidizables and autopolymerizable materials minimizes this higher risk inventory. Annual reconciliation of the inventory provides a review of the general condition of all containers and the storage conditions of these materials to minimize the risk of container failure and incompatible storage.

\section{b. Probability of Occurrence}

Given that the nature of SNL/CA's business entails the use of some extremely hazardous materials, and given the very low thresholds of some of these materials for requiring an Emergency Management Hazards Assessment, the probability of being required to prepare and implement an Emergency Management Hazardous Materials Program is considered to be High. Chemical safety issues relating to improper storage or the accidental release of hazardous materials impacting personnel and/or the environment from excess inventory is also considered to have a HIGH probability of occurrence.

\section{c. Consequence of Occurrence}

The preparation and implementation of a site-wide Emergency Management Hazardous Materials Program would very likely entail costs in the range of several hundred thousand dollars per year. These costs would be primarily borne by the Site Operations Center, since most of the activities would be carried out by the Security Operations Department and the ES\&H departments. This cost would be less than 5\% of the Site Operations budget (\$45 million in 2010), so the consequence assigned is LOW.

\section{d. Overall Risk Category}

In accordance with the chart above, for a risk with a probability of High and a Low consequence, the risk category is MEDIUM.

\section{Site-wide Earthquake Induced Spill or Accident}

\section{a. Identification of Risk}

Incidents, such as spills and fires are not unknown due to earthquakes at facilities.

\section{b. Probability of Occurrence}

Given the recent history, the probability of occurrence is considered Low that an earthquake of sizable magnitude will occur affecting SNL/CA at some time during the lifetime of the SNL/CA facility. A moderate earthquake in 1980 caused significant damage to SNL/CA include minor chemical spillage. 


\section{c. Consequence of Occurrence}

SNL/CA would be responsible for the on-site clean-up and cost of waste disposal. A post cleanup inventory reconciliation would be required to verify the accuracy of the remaining inventory costing about $\$ 50 \mathrm{k}$ would be required. It is assumed that the dollar amount of the SNL/CA liability would be less than 1\% of the SNL/CA annual operating budget (\$250 million in FY 2010), therefore the consequence is Low.

\section{d. Overall Risk Category}

In accordance with the chart above, for a risk with a probability of Low, with a Medium severity, the risk category is LOW.

\section{Reduction in Program Funding by $10 \%$}

\section{a. Identification of Risk}

SNL/CA is experiencing pressure to reduce expenses for indirect-funded and directfunded organizations, including Environmental Management. Because the majority of Hazardous Material Management Program expenditures are for labor, a 10\% reduction in funding would impact staffing. A reduction in staffing would result in a reduced level of service to line organizations.

\section{b. Probability of Occurrence}

Increasing constraints on site budgets is expected to continue for the next several years. Consequently the probability that funding for the Hazardous Materials Management Program will decrease by 10\% from FY 2010 levels is

\section{c. Consequence of Occurrence}

A $10 \%$ reduction in program funding would result in decreased staffing, training, and purchases. Only those program activities that are required by regulation, Sandia policy, technical work documents, or DOE/NNSA would be conducted. Discretionary training and travel for program staff would be eliminated. Purchases for replacement equipment and equipment repair would be reduced. A reduction in Line training and support would occur. The suspension of the Summer Reconciliation would be likely because Summer Interns would not be hired.

An occurrence could occur as a result Line under compliance and documentation inaccuracies. For these reasons, the consequence of a $10 \%$ reduction in program funding is identified as Medium.

\section{d. Overall Risk Category}


In accordance with the chart above, for a risk with a probability of High, with a Low severity, the risk category is HIGH.

\section{Regulatory Noncompliance}

\section{a. Identification of Risk}

The Fire Protection Program was identified during the Fall 2008 Alameda County Department of Environmental Health (SNL/CA CUPA) Assessment to be under managing hazardous materials according to the California Fire Code (CFC). A similar situation exists with the International Fire Code (IFC) that is regulated by DOE. This situation has been improved by report modifications in CIS. Full CFC compliance, however, is difficult without comprehensive hazard categorization data that is not available for all the hazardous materials on site. This identified risk is dependent on the extent the CUPA chooses to regulate the CFC at SNL/CA. All California facilities struggle with these regulations and full compliance.

\section{b. Probability of Occurrence}

The probability of an EPA, DOE, or Alameda County audit resulting in a fine and/or negative publicity is Low.

\section{c. Consequence of Occurrence}

The consequence of a fine and/or negative publicity would likely be an "Unallowable cost or fine $<\$ 500 \mathrm{~K}$ " and the "adverse public opinion would be short-term local negative publicity or embarrassment”. Therefore, the consequence is identified as Low.

\section{d. Overall Risk Category}

In accordance with the chart above, for a risk with a probability of Low, with a Low severity, the risk category is LOW. 


\title{
Appendix C. Hazardous Materials Management Quality Significant Purchases Determination
}

\author{
团 Sandia National laboratories \\ Operated for the U.S. Department of \\ Energy by Sandia Corporation \\ Livermore, California 94551-0969
}

date: March 24, 2006

to: Gary Shamber, 8516

Manager, Environmental Management Department

from: Mark Brynildson, 8516

Hazardous Material Management Program Lead

subject: Quality Significant Purchases

1.Program title. Hazardous Material Management Program

2. Risk level of the program: The highest risk level was determined to be medium.

3. Types of material/instruments/equipment used in the program:

- PPE

- Communication devices (phones \& pagers)

- Barcodes and Barcode Scanners

- CIS database

- Desktop computers and printers

4. Criteria used to evaluate these to determine quality significance:

A potential failure of the items listed was evaluated against corporate quality-significant criteria. It was determined that such a failure:

$>$ Will not cause a significant adverse impact to program cost, schedule, or performance in the event of a failure;

$>$ Will not significantly impact the safe operation of a facility or activity;

$>$ Will not involve the use, handling, or storage of radioactive material or radiationgenerating devices, or involve exposure to ionizing radiation;

$>$ Do not relate to the design, analysis, manufacture, or assembly of hardware, equipment, and software for present or future use with radioactive material;

$>$ Will not be used in any safety-significant or safety-critical system, component, or application whose failure could adversely affect people, property, or the environment. 
5. Determination on quality significant items: The Hazardous Material Management Program does not have any quality significant items.

6. Determination on S/CI concerns/issues: The Hazardous Material Management Program does not have items that have the potential for suspect/counterfeit items that would be of a concern to the program. 


\title{
Appendix D. Hazardous Materials Management Program Self Assessment
}

\author{
LESA Assessment Final Report \\ Assessment ID: 11261
}

8516 EMS Hazardous Material Management FY11

\author{
Assessment Summary \\ ID: $\quad 11261$ \\ Title: $\quad 8516$ EMS Hazardous Material Management FY11 \\ Description: Division 8000 Hazardous Material Management Annual Program \\ Assessment SNL/CA Chemical Procurement and Receiving. Topics to \\ be assessed are: Standard Program Document review: TWDs and web \\ pages Process Level Assessment:... \\ Purpose: $\quad$ Division 8000 Hazardous Material Management Annual Program Self- \\ Assessment on an Integrated Assessment Schedule. In early, 2010, \\ the Chemical Receiving process was significantly changed at SNL/CA \\ with the introduction o... \\ Originating \\ Mgt. Entity: Division » 8000 California Laboratory

$\begin{array}{llll} & \text { Org } & \text { Manager } & \text { Division } \\ \text { Assessing Org: } & 08516 & \text { Shamber,Gary W. } & 08000 \\ & & & \\ \text { Org(s) Being } & \text { Org } & \text { Manager } & \text { Division } \\ \text { Assessed: } & 08516 & \text { Shamber,Gary W. } & 08000\end{array}$ \\ Lead Assessor: Ayers, Susanne L. (08516) \\ POC Assessed: None \\ Type: Line Assess the Line \\ Status: In Progress \\ Dates: $\quad 10 / 14 / 2010-12 / 20 / 2010$ \\ Result 0 Significant Findings, 0 Minor Findings, 2 Observations, \\ Summary: 1 Noteworthy Practices, 1 None (Acceptable Practices) \\ I A 0 Required I As Missing, 1 On Track IAs, 0 Past Due IAs, \\ Summary: $\quad 1$ Causal Analyses
}


Submitted To: $\quad$ Shamber, Gary W. (08516)

Submitted By: Ayers,Susanne L. (08516)

Submitted Date: 12/23/2010

\section{Assessment Detail}

\section{Description}

Division 8000 Hazardous Material Management Annual Program Assessment

SNL/CA Chemical Procurement and Receiving.

Topics to be assessed are:

Standard Program Document review: TWDs and web pages

Process Level Assessment: Assessment of Chemical Procurement and Receiving Process including the LLNL \& SNL/CA Chemical Receiving J oint Operations.

\section{Purpose}

Division 8000 Hazardous Material Management Annual Program Self-Assessment on an Integrated Assessment Schedule.

In early, 2010, the Chemical Receiving process was significantly changed at SNL/CA with the introduction of J oint Operations with LLNL. The supply chain process was also changed but not fully implemented with the new corporate JIT Chemical Procurement contract change. An assessment of these important supply chain changes will evaluate the effectiveness of these process changes and identify opportunities for improvement.

\section{Analysis, Conclusions, and Additional Comments}

Analysis/Conclusions:

During this assessment, a review of the chemical receiving SNL/CA joint operations with LLNL and supply chain process was completed. With the initial consolidation of joint operations, problems rose in the chemical receiving operations. Since then CIS/HMMP and Logistics have worked jointly to resolve these issues and come up with alternative solutions. However, one remaining issue lies with the separation of logistics and chemical receiving operations which has lead to a breakdown in communication between the two groups. Once the new corporate JIT contract is fully implemented at SNL/CA, we hope that it will improve the chemical receiving process and resolve any remaining issues.

\section{Location(s) Assessed}

None

\section{Scope/ Criteria}

- ES\&H » Industrial Hygiene » Chemical Information System

- ES\&H » Industrial Hygiene » Chemical Barcoding \& Inventory

- $\mathrm{ES \& H} \gg$ Environmental Protection » Environmental Management System

\section{Checklist Used}


None

\section{Associated Document Link(s)}

None

\section{Assessment Team Members}

$\begin{array}{llll}\text { Name } & \text { Org. } & \text { Role } & \text { Additional Role Description } \\ \text { AYERS, SUSANNE L. } & 08516 & \text { Assessor } & \\ \text { BRYNILDSON,MARK E. } & 08516 & \text { Assessor } & \\ \text { AYERS, SUSANNE L. } & 08516 & \text { Creator } & \end{array}$

\section{Personnel I nterviewed}

None

\section{Documents Reviewed}

\begin{tabular}{|c|c|c|c|c|c|}
\hline Document & Number & Description & Revisior & Type & Date of Review \\
\hline $\begin{array}{l}\text { CIS/HMMP } \\
\text { Procedures }\end{array}$ & AP800003 & $\begin{array}{l}\text { CIS/HMMP } \\
\text { procedures for } \\
\text { reconciliation, } \\
\text { highly } \\
\text { hazardous } \\
\text { matierals, \& } \\
\text { daily inventory }\end{array}$ & $\mathrm{C}$ & AP & TBD \\
\hline $\begin{array}{l}\text { Hazardous } \\
\text { Material } \\
\text { Management } \\
\text { Program at } \\
\text { SNL/CA }\end{array}$ & $\begin{array}{l}\text { SNLOA00433- } \\
014\end{array}$ & & & PHS & $09 / 15 / 2010$ \\
\hline $\begin{array}{l}\text { Semi-annual Fire } \\
\text { Run Card } \\
\text { Hazardous } \\
\text { Materials Revi }\end{array}$ & OP471758 & $\begin{array}{l}\text { Semi-annual } \\
\text { Fire Run Card } \\
\text { Hazardous } \\
\text { Materials Review }\end{array}$ & E & OP & $10 / 18 / 2010$ \\
\hline CIS Homepage & & CIS Webpages & 1.1 .20 & Webpage & $10 / 19 / 2010$ \\
\hline CIS Forms & & CIS Forms & & Forms & $10 / 26 / 2010$ \\
\hline $\begin{array}{l}\text { Corporate } \\
\text { Procedure: } \\
\text { ESH100.2.IH.20 }\end{array}$ & ESH100.2.IH.20 & $\begin{array}{l}\text { Maintain an } \\
\text { Accurate } \\
\text { Chemical and } \\
\text { Biological } \\
\text { material } \\
\text { Inventory }\end{array}$ & & & $10 / 19 / 2010$ \\
\hline
\end{tabular}




\section{Significant Findings}

This Assessment resulted in 0 Significant Finding(s).

\section{Minor Findings}

This Assessment resulted in 0 Minor Finding(s).

\section{Observations}

This Assessment resulted in 2 Observation(s).

\section{Observation No. 1}

On 2/1/10, LLNL and SNL/CA joined shipping, receiving and mail service operations. With the joint operations, LLNL will receive, process, and separate all SNL/CA packages. SNL/CA Material Handlers (MH) will make two daily trips to LLNL to pick-up packages and deliver chemical packages to the $\mathrm{CIS}$ desk for barcoding. $\mathrm{MH}$ will deliver chemical packages to the Line once they have been processed by $\mathrm{CIS}$ personnel. Prior to the joint operations chemical packages were received by $\mathrm{MH}$ and processed by $\mathrm{CIS}$ no later than 11:00am. Chemical packages were loaded on MH trucks and ready for afternoon delivery. Any chemical package that needed to be traced, CIS personnel took the initiative and traced that package to prevent any delay in delivery of the material. With $\mathrm{CIS}$ personnel and $\mathrm{MH}$ physically located in one location, we were able to communicate quickly and directly with one another about any issues or concerns regarding packages. Once the joint operations were implemented, processes were changed for Logistics and $\mathrm{CIS}$. Logistics was now responsible for handling all chemical traces. MH would drop off chemical packages to the CIS desk after 1:15 pm, which were then processed by $\mathrm{CIS}$ personnel, and then delivered to the Line after $2 \mathrm{pm}$. If the chemical package needed to be traced, then it could take up to an additional day to complete this process. With the joint operations in place, many customers were not pleased with receiving their chemical packages (especially temperature sensitive materials) so late in the day. Logistics worked with LLNL to help improve this process. MH drops off chemical packages to the CIS desk by 11:15 am, where they are processed and ready for delivery by $1 \mathrm{pm}$. With Logistics handling chemical traces and physically located in a separate location, we seen the first failure in this new process. This process failed when it $\mathrm{MH}$ and $\mathrm{CIS}$ personnel failed to communicate to $\mathrm{Jim}$ Prestwood that a temperature sensitive needed to be traced. The package resided in the CIS freezer for several days before it was traced and delivered to the customer. Logistics and CIS agreed that all chemical traces will be handled by $\mathrm{CIS}$ personnel (backed up by Logistics) to help prevent future delays in 
delivery. When $\mathrm{CIS}$ personnel are unavailable, $\mathrm{MH}$ will document and direct deliver all temperature sensitive/perishable chemical packages. Logistics and CIS have worked to improve issues and concerns, but with the groups physically being located in different location it makes direct communication between the groups more difficult.

Trending Code: Work Processes

\section{Result Location(s):}

None

Result Criterion: ES\&H » Industrial Hygiene » Chemical Barcoding \& Inventory

\section{Result Associated Document Link(s):}

None

\section{I mprovement Actions(s):}

There are no Improvement Actions.

\section{Observation No. 2}

As of July 1, 2010, a new corporate JIT chemical procurement contract went into effect. This new JIT contract outsources the chemical procurement by having the Line place orders through the JIT chemical vendor, who place the order, barcode the chemical at their local facility, and then direct deliver the chemical package. With the new contract in place, it should help improve the issues related to the new joint operations with LLNL like improving the delivery time of chemicals and handling all chemical traces prior to delivery of chemicals. Unfortunately, the new corporate contract has not been fully implemented at SNL/CA. When this new contract went into effect, SNL/CA had an existing procurement contract in place that SNL/CA Procurement chooses to extend and operate under. Since JIT corporate is administered in SNL/NM, there is no local representative in SNL/CA to handle issues/concerns and push the implementation of this contract. In order to move forward with this corporate contract, JIT Procurement at $\mathrm{SNL} / \mathrm{NM}$ needs to work with Procurement at SNL/CA to resolve any issues.

Trending Code: Work Processes

\section{Result Location(s):}

None

Result Criterion: ES\&H » Industrial Hygiene » Chemical Information System

\section{Result Associated Document Link(s):}

None

\section{I mprovement Actions(s):}

I A No: 11261-02-IA1

I A Type: Further Action Required I A Status: Open 
Owner: Name: Ayers, Susanne L. Org: 08516 Assigned Date: 11/29/2010 Estimated Completion Date: 03/31/2011 Revised Completion Date: n/a Actual Completion Date: TBD

Description: The corporate JIT chemical procurement will be implemented at SNL/CA.

Comments: None

Causal Analysis Summary: Since JIT corporate is administered in SNL/NM, there is no local representative in SNL/CA to handle issues/concerns and push the implementation of this contract at SNL/CA. To move forward and insure that this contract is implemented at SNL/CA, management assigned Susie Ayers as the Sandia Delegated Representative (SDR) for California.

Causal Analysis Associated Document Link(s): None

\section{A Associated Document Link(s):}

None

Actions taken to verify satisfactory completion:

TBD

Evaluation of improvement actions (satisfactory completion, not satisfactory / why):

TBD

Verified By: Name: TBD Org: TBD Verification Date: TBD

\section{Notew orthy Practices}

This Assessment resulted in 1 Noteworthy Practice(s).

\section{Noteworthy Practice No. 1}

The Hazardous Material Management EMS Target for FY10 was to maintain an annual overall CIS reconciliation of $>94 \%$ and $100 \%$ for the NFPA 704 Health Hazard Rated 4 materials greater than $10 \%$ of laboratory scale quantities. The HMMP successfully meet both of these goals. For FY10, the annual CIS reconciliation ended with $95 \%$ inventory accuracy and accounted for all of the NFPA Health Hazard Rated 4 materials greater than $10 \%$ of lab scale quantities.

\section{Result Location(s):}

None

Result Criterion: ES\&H » Industrial Hygiene » Chemical Barcoding \& Inventory

\section{Result Associated Document Link(s):}

None 
None (Acceptable Practices)

This Assessment resulted in 1 None(s) (Acceptable Practices).

\section{None - Acceptable Practice No. 1}

The Hazardous Materials Management Program documents (PHS, administrative procedure, operating procedure, forms, web pages, and Corporate Procedure: ESH100.2.IH.20 Maintain an Accurate Chemical and Biological Material Inventory have been reviewed and updated as needed. 


\title{
Appendix E. Hazardous Materials Management Program Self Assessment Document Checklist
}

\author{
Organization: \\ 8516 \\ Program: Hazardous Material Management
}

Date: _ Signature: Mark Brynildson/Susie Ayers

\begin{tabular}{|c|c|c|c|c|}
\hline $\begin{array}{l}\text { Document } \\
\text { Type }\end{array}$ & Document Title & $\begin{array}{l}\text { Review } \\
\text { Complete } \\
\text { / Date } \\
\end{array}$ & $\begin{array}{l}\text { Changes } \\
\text { Made }\end{array}$ & Comments \\
\hline \multirow[t]{2}{*}{$\begin{array}{l}\text { Operating } \\
\text { Procedures }\end{array}$} & AP800003 - CIS/HMMP Procedures Version B & $\begin{array}{l}\searrow \\
10 / 18 / 10\end{array}$ & $\begin{array}{l}\square \text { Yes } \\
\square \text { No }\end{array}$ & $\begin{array}{l}\text { AP is being updated to } \\
\text { reflect new delivery } \\
\text { process }\end{array}$ \\
\hline & $\begin{array}{l}\text { OP471758 - Semi-Annual Fire Run Card Hazardous } \\
\text { Materials Review Version E }\end{array}$ & $\begin{array}{l}\bigotimes \\
10 / 18 / 10\end{array}$ & $\square_{\text {No }}$ & \\
\hline PHS & $\begin{array}{l}\text { Hazardous Material Management Program Operations at } \\
\text { SNL/CA (SNL0A00433-014) }\end{array}$ & $\begin{array}{l}\bigotimes \\
9 / 13 / 10\end{array}$ & $\square_{\text {No }}$ & \\
\hline \multirow{9}{*}{$\begin{array}{l}\text { Other } \\
\text { Program } \\
\text { Documents }\end{array}$} & $\begin{array}{l}\text { Corporate Procedure: ESH100.2.IH.20 Maintain an } \\
\text { Accurate Chemical and Biological Material Inventory }\end{array}$ & $\bigotimes_{10 / 19 / 10}$ & $\begin{array}{l}\square \text { Yes } \\
\nabla_{\text {No }}\end{array}$ & \\
\hline & $\begin{array}{l}\text { CIS Program Plan (HMMP Annual Report) } \\
\text { SAND2010-1463 }\end{array}$ & $\begin{array}{l}\square \\
10 / 19 / 10\end{array}$ & $\begin{array}{l}\square \text { Yes } \\
\square \text { No }\end{array}$ & $\begin{array}{l}\text { Some hyperlinks that } \\
\text { don't work - Plan will be } \\
\text { updated }\end{array}$ \\
\hline & $\begin{array}{l}\text { Static Inventory Form (pdf/word) } \\
\text { http://info.sandia.gov/corpdata/corpforms/2001cif.pdf } \\
\text { http://info.sandia.gov/corpdata/corpforms/2001cif.dot }\end{array}$ & $\begin{array}{l}\bigotimes \\
10 / 25 / 10\end{array}$ & $\square_{\text {No }}$ & \\
\hline & $\begin{array}{l}\text { Gas Cylinder Form (pdf/word) } \\
\text { http://info.sandia.gov/corpdata/corpforms/2001cig.pdf } \\
\text { http://info.sandia.gov/corpdata/corpforms/2001cig.dot }\end{array}$ & $\begin{array}{l}\square \\
10 / 25 / 10\end{array}$ & $\begin{array}{l}\square \text { Yes } \\
\text { No }\end{array}$ & \\
\hline & $\begin{array}{l}\text { Chemical Inventory Incoming Form (pdf/word) } \\
\text { http://info.sandia.gov/corpdata/corpforms/2001cii.pdf } \\
\text { http://info.sandia.gov/corpdata/corpforms/2001cii.dot }\end{array}$ & $\begin{array}{l}\bigotimes \\
10 / 25 / 10\end{array}$ & $\square_{\text {Nos }}$ & \\
\hline & $\begin{array}{l}\text { Biological Agent Inventory form (pdf/word) } \\
\text { http://info.sandia.gov/corpdata/corpforms/2001bai.pdf } \\
\text { http://info.sandia.gov/corpdata/corpforms/2001bai.doc }\end{array}$ & $\begin{array}{l}\square \\
10 / 25 / 10\end{array}$ & $\square$ Yes & \\
\hline & $\begin{array}{l}\text { Location Description form (pdf/word) } \\
\text { http://info.sandia.gov/corpdata/corpforms/2001cil.pdf } \\
\text { http://info.sandia.gov/corpdata/corpforms/2001cil.dot }\end{array}$ & $\begin{array}{l} \\
10 / 25 / 10\end{array}$ & \begin{tabular}{|l} 
Yes \\
No
\end{tabular} & \\
\hline & $\begin{array}{l}\text { Chemical Transfer/Disposal form (pdf/word) } \\
\text { http://info.sandia.gov/corpdata/corpforms/2001cit.pdf } \\
\text { http://info.sandia.gov/corpdata/corpforms/2001cit.dot }\end{array}$ & $\begin{array}{l}\bigotimes_{10 / 25 / 10} \\
\end{array}$ & $\square_{\text {No }}$ & \\
\hline & $\begin{array}{l}\text { SNL Generated MSDS Request Form (pdf/word) } \\
\text { http://info.sandia.gov/corpdata/corpforms/2001msr.pdf } \\
\text { http://info.sandia.gov/corpdata/corpforms/2001msr.dot }\end{array}$ & $\begin{array}{l}\square_{10 / 25 / 10} \\
\end{array}$ & $\begin{array}{l}\square \text { Yes } \\
\text { No }\end{array}$ & \\
\hline \multirow[t]{2}{*}{ Web Pages } & $\begin{array}{l}\text { General Web Page } \\
\text { http://info.sandia.gov/centers/8500/esh/CA- } \\
\text { EnvMgmt/programs/HM }\end{array}$ & $\begin{array}{l}\bigotimes_{10 / 19 / 10} \\
\end{array}$ & $\square_{\text {Nos }}$ & \\
\hline & $\begin{array}{l}\text { Program Web Pages } \\
\text { https://webprod.sandia.gov/CIS/svStartup }\end{array}$ & $\begin{array}{l}\square_{10 / 19 / 10} \\
\end{array}$ & $\begin{array}{l}\square \text { Yes } \\
\square \text { No }\end{array}$ & \\
\hline
\end{tabular}


Hazardous Materials Management Program Annual Report

February 2011

\section{Distribution:}

MS 9002 Smith, Patricia N., 08500

MS 9956 Garcia, John., 08510

MS 9902 Shamber, Gary W., 08516

MS 0899 Technical Library, 09536 (electronic copy) 